Discussion Paper No. 1036

\title{
CURRENT ACCOUNT DYNAMICS UNDER INFORMATION RIGIDITY AND IMPERFECT CAPITAL MOBILITY
}

\author{
Akihisa Shibata \\ Mototsugu Shintani \\ Takayuki Tsuruga
}

July 2018

The Institute of Social and Economic Research Osaka University

6-1 Mihogaoka, Ibaraki, Osaka 567-0047, Japan 


\title{
Current Account Dynamics under Information Rigidity and Imperfect Capital Mobility*
}

\author{
Akihisa Shibata†, Mototsugu Shintani; and Takayuki Tsuruga ${ }^{\S}$ \\ This draft: July 2018
}

\begin{abstract}
The current account in developed countries is highly persistent and volatile in comparison to output growth. The standard intertemporal current account model with rational expectations (RE) fails to account for the observed current account dynamics together with persistent changes in consumption. The RE model extended with imperfect capital mobility by Shibata and Shintani (1998) can account for persistent changes in consumption, but only at the cost of the explanatory power for the volatility of the current account. This paper replaces RE in the intertemporal current account model with sticky information (SI) in which consumers are inattentive to shocks to their income and infrequently adjust their consumption. The SI model can better explain a persistent and volatile current account than the RE model but it overpredicts the persistence of changes in consumption. The SI model extended with imperfect capital mobility almost fully explains current account dynamics and the persistence of changes in consumption, if high degrees of information rigidity and imperfect capital mobility are taken into account.
\end{abstract}

JEL Classifications: E21, F21, F32, F41

Keywords: Capital mobility, Imperfect information, Inattentiveness, Permanent income hypothesis

${ }^{*}$ We thank Takashi Kano, Eiji Okano, Jun Nie, and seminar and conference participants at the Cabinet Office (Government of Japan), Otaru University of Commerce, Shiga University, the University of Tokyo, and the Asian Meeting of the Econometric Society, Annual Meeting of Japan Society of Monetary Economics, and Econometric Society Australasian Meeting for helpful comments and discussions. The authors greatly acknowledge the financial support of Grant-in-aid for Scientific Research (16H02026, 15H05729, 15H05728, and 18K01684). Akihiko Ikeda provided excellent research assistance. All remaining errors are our own.

${ }^{\dagger}$ Kyoto University; e-mail: shibata@kier.kyoto-u.ac.jp.

${ }^{\ddagger}$ Corresponding author. The University of Tokyo; e-mail: shintani@econ.rcast.u-tokyo.ac.jp.

${ }^{\S}$ Osaka University; e-mail: tsuruga@iser.osaka-u.ac.jp. 


\section{Introduction}

The persistent and volatile current account surplus and deficit have attracted the attention of researchers and policymakers because they are associated with a large imbalance in international trade, or global capital inflows and outflows. Despite this considerable attention, the standard intertemporal current account (ICA) model has only limited success in accounting for the persistent and volatile current account. ${ }^{1}$ A reason for the limited success of the standard ICA model is that the model depends on the permanent income hypothesis. Under the permanent income hypothesis, changes in consumption are unpredictable, but the changes in consumption observed in developed countries are often predictable. ${ }^{2}$ Such predictable changes in consumption have often been explained by hand-to-mouth consumers who have only limited access to financial markets (e.g., Campbell and Mankiw 1989, 1990). ${ }^{3}$ In the context of the ICA model, limited access to financial markets means that international capital mobility is imperfect. Shibata and Shintani (1998) study the ICA model with imperfect international capital mobility. They estimate the degree of imperfect capital mobility, which can be translated into the fraction of hand-to-mouth consumers in the economy.

The objective of this paper is to understand theoretically how the ICA model can better explain current account dynamics. The data of OECD countries indicate that the current account is much more persistent and volatile than net output growth. ${ }^{4}$ We show that the ICA model with rational expectations (RE) underpredicts the persistence and volatility of the current account. As in Shibata and Shintani (1998), we introduce imperfect capital mobility by combining forward-looking consumers and hand-to-mouth consumers. We argue that this hybrid RE model can explain persistent consumption growth but achieve this prediction only at the cost of undermining the predicted volatility of the current account.

To better explain current account dynamics, we replace RE in the ICA model with sticky information (SI) as developed by Mankiw and Reis (2002, 2007) and Reis (2006). In the literature on the permanent income hypothesis, a number of previous studies have argued for the role of inattentiveness to shocks (e.g., Pischke, 1995, Sims, 2003, Reis, 2006, Carroll and Slacalek, 2007, Luo, 2008, Sims, 2010, Luo, Nie, and Young, 2015, and Gabaix, 2016, among others). In these previous studies, agents are subject to information rigidities and

\footnotetext{
${ }^{1}$ See Nason and Rogers (2006) and the reference therein.

${ }^{2}$ Carroll, Slacalek, and Sommer (2011) provide robust evidence on the persistence of consumption growth.

${ }^{3}$ For the international evidence on hand-to-mouth consumers, see Campbell and Mankiw (1991). The theoretical implications for hand-to-mouth consumers have been explored well in the general equilibrium models (e.g., Galí, López-Salido and Vallés 2004, 2007 and Bilbiie 2008).

${ }^{4}$ Net output in the ICA model is obtained by subtracting investment and government spending from output. For a more formal definition, see Section 2.
} 
inattentive to income shocks. The resulting consumption does not follow a random walk and the changes in consumption are predictable, depending on the degree of information rigidity. Overall, consumption dynamics with information rigidities are shown to fit the data of aggregate consumption well, in comparison to the RE model.

Following this line of research, we explore current account dynamics under the SI model, one of the simplest models of information rigidity. Under SI, consumers cannot update their information with a constant probability. Consequently, some consumers are inattentive to news and such inattentive consumers stick to the consumption level planned in the past period. We demonstrate that the SI model can explain a persistent and volatile current account but it tends to overpredict persistent changes in consumption. We show that the hybrid SI model that combines forward-looking consumers with SI and hand-to-mouth consumers generates moderately persistent consumption growth without undermining predictions of the current account. If we allow for a high degree of imperfect information and imperfect capital mobility, the hybrid SI model can almost fully explain current account dynamics along with persistent consumption growth.

At least two important recent studies on open macroeconomy are closely related to our work in terms of the importance of information rigidity. ${ }^{5}$ The first is Luo, Nie, and Young (2012) who extend the ICA model with rational inattention and robustness. ${ }^{6}$ While our paper is similar to theirs in that economic agents in our model imperfectly observe state variables, the primary focus of Luo, Nie, and Young (2012) is on how robustness, that is, the uncertainty on the model economy, improves the ICA model's prediction and its interaction with rational inattention. ${ }^{7}$ The other important contribution is Ekinci (2017) who develops the general equilibrium model under SI. His analysis of SI is motivated by explaining the well-known puzzles in the two-country, open-economy models, such as the real exchange

\footnotetext{
${ }^{5}$ We also note that, apart from information rigidity, a number of the previous studies have investigated explanations for current account dynamics and are thus closely related to our paper. Examples include Glick and Rogoff (1995), Ghosh and Ostry (1997), Bergin and Sheffrin (2000), Işcan (2002), Gruber (2004), Kunieda and Shibata (2005), and Kano (2008, 2009).

${ }^{6}$ See also a recent work by Li, Luo, and Nie (2017) who use the rational inattention and study international consumption comovement puzzle.

${ }^{7}$ Luo, Nie, and Young (2012) argue that the current account detrended by the Hodrick-Prescott (HP) filter tends to be less persistent than the standard RE model predicts. By contrast, we argue that the current account scaled by net output tends to be more persistent than the standard RE model implies. On top of the definition of variables, the difference from Luo, Nie, and Young's (2012) argument also stems from difference in the assumption on the stochastic process of net output. In particular, while Luo, Nie, and Young (2012) focus on the case where the net output detrended by the HP filter follows a stationary $\operatorname{AR}(1)$ process or a random walk, we consider the case where net output growth follows the AR(1) process so that a stochastic trend is always present as in other previous works in the literature. For example, see Sheffrin and Woo (1990), Otto (1992), Ghosh (1995), Ghosh and Ostry (1997), Bergin and Sheffrin (2000), and Gruber (2004).
} 
rate volatility puzzle and the Backus-Smith puzzle. In contrast, our analysis of SI aims to understand the persistence and volatility of the current account in small open-economy models. ${ }^{8}$

This paper is organized as follows. In Section 2, we provide the evidence on current account dynamics. Section 3 reviews the RE model. We discuss that the model is difficult to reconcile with the data. In Section 4, we describe the SI model. Section 5 assesses the empirical performance of the SI and hybrid SI models. Section 6 concludes our analysis.

\section{Evidence}

The data source is the annual data from 16 OECD countries over 1980-2013 taken from the International Financial Statistics of the International Monetary Fund. The selected countries are also included in the previous empirical studies such as Sheffrin and Woo (1990), Ghosh (1995), and Shibata and Shintani (1998), among others. Our sample of developed countries includes Australia, Austria, Belgium, Canada, Denmark, Finland, France, Germany, Iceland, Italy, Japan, the Netherlands, Norway, Sweden, UK, and US. ${ }^{9}$ Here, current account data are constructed from gross national income minus the sum of the household final consumption expenditure, gross capital formation, and government final consumption expenditure. ${ }^{10}$ The net output is defined by the gross domestic product (GDP) minus the sum of gross capital formation and government final consumption expenditure. Consumption is the household final consumption expenditure, including non-profit institutions serving households. All the series are converted to real series with the GDP deflator and measured in per capita terms. ${ }^{11}$

In our empirical analysis, the current account is normalized by the net output. This

\footnotetext{
${ }^{8}$ See also Crucini, Shintani, and Tsuruga (2010) who assume SI and sticky prices in firms' price setting and explain the persistence and volatility of good-level real exchange rates.

${ }^{9}$ We select these countries based on the following criteria: First, the number of observations of the current account exceeds 30. Second, the sample countries are classified as rich countries based on Uribe and SchmittGrohé (2017). Third, the mean growth rate of net output over $1980-2013$ is less than 4 percent. The last criterion is employed because the numerical exercise in Section 5 requires that the mean growth rate of net output be low in comparison to the world interest rate.

${ }^{10}$ The only exception is the Netherlands, where gross national income is not available in the International Financial Statistics. For this country, we take current account data based on Balance of Payments Manual Fifth edition (BPM5) from the OECD website. To be consistent with the data source, the data from the OECD website is also used for constructing the net output for the Netherlands.

${ }^{11}$ If we use quarterly data, net output and the current account constructed from the seasonally-adjusted series of the GDP, consumption, investment, and the government expenditure do not match the seasonallyadjusted series of net output and the current account. However, raw data (before the seasonal adjustment) are not typically available so that seasonally adjusted series of net output and the current account cannot be constructed for many countries. For this reason, we do not use the quarterly data but focus on the analysis based on annual data.
} 
normalization is useful in describing the current account dynamics, particularly when the growth rate of net output is stationary. ${ }^{12}$ A similar normalization was first employed by Campbell and Deaton (1989) in the context of the optimal saving rate under the permanent income hypothesis when labor income growth is stationary. For the same reason, we also express changes in consumption as a fraction of lagged net output. The same reformulation of consumption change has also been used by Shibata and Shintani (1998) in their analysis of ICA model with imperfect capital mobility.

Table 1 assesses current account dynamics in the sample countries. In the table, we report the cross-country average of persistence and volatility of the current account, along with the persistence of net output growth and changes in consumption. The persistence of the current account is measured by the first-order autocorrelation, denoted by $\rho_{c a}^{\text {data }} \cdot{ }^{13}$ Volatility is measured by the standard deviation ratio of the current account to net output growth. We denote the volatility measure by $V_{c a}^{\text {data }}$. In this measure, when the current account is more volatile than the net output growth, $V_{c a}^{\text {data }}$ exceeds one.

Table 1 indicates that the current account is much more persistent and volatile than the net output growth. We see that the observed persistence of the current account $\left(\rho_{c a}^{\text {data }}\right)$ is 0.82 , which is much more persistent than that of the net output growth of $0.16\left(\phi^{\text {data }}\right)$. While the table reports, for brevity, only the persistence averaged across countries, these inequalities are preserved for all single-country data. When we examine the volatility, the current account is about twice as volatile as the net output growth. In terms of the singlecountry data, the volatility of the current account in all countries except for Japan exceeds unity. We note that the persistence of changes in consumption $\left(\rho_{\Delta c}^{\text {data }}\right)$ deviates from zero, and is 0.25 on average.

\section{The RE models}

In this section, we present RE models, focusing on the persistence and volatility of the current account.

\subsection{Setup}

Consider a small open economy inhabited by a continuum of identical consumers located in a unit interval. A consumer's lifetime expected utility is $\mathbb{E}_{t} \sum_{j=0}^{\infty} \beta^{j} u\left(C_{t+j}\right)$ where $C_{t}$ denotes

\footnotetext{
${ }^{12}$ We remove the stochastic trend in the net output by the log difference rather than Hodrick-Prescott filter, in contrast to Luo, Nie, and Young (2012).

${ }^{13}$ Here, we measure the first-order autocorrelation using the OLS estimator of the AR(1) model.
} 
consumption and $\beta$ is the discount factor satisfying $\beta \in(0,1)$. Also, $\mathbb{E}_{t}[\cdot]$ represents the expectations operator conditional on the information available in period $t$. Following Uribe and Schmitt-Grohé (2017), we specify $u(\cdot)$ as $u\left(C_{t}\right)=-0.5\left(C_{t}-\bar{C}\right)^{2}$, where $\bar{C}$ is the bliss point so that $C_{t}<\bar{C}$ for all $t$. The consumers' flow budget constraint is

$$
A_{t+j+1}=(1+r) A_{t+j}+X_{t+j}-C_{t+j}
$$

for all $j>0$. Here, $A_{t}$ denotes foreign asset holdings at the beginning of period $t$. In this budget constraint, consumers have access to perfect international capital markets where capital can be saved or borrowed at a constant world interest rate $r$. To facilitate the analysis, we assume that the rate of time preference is equal to $r: \beta=1 /(1+r)$. Finally, $X_{t}$ is the exogenous stochastic endowment which we can also interpret as net output.

The first-order condition implies that $C_{t}=\mathbb{E}_{t} C_{t+j}$ for $j=1,2, \ldots$. The optimal consumption is given by

$$
C_{t}=r A_{t}+X_{t}^{p}
$$

where $X_{t}^{p}$ is the non-financial permanent income given by $X_{t}^{p}=[r /(1+r)] \sum_{j=0}^{\infty}(1+r)^{-j} \mathbb{E}_{t} X_{t+j}$. Changes in consumption are calculated as $\Delta C_{t+1}=\Delta \mathbb{E}_{t+1} X_{t+1}^{p}$, where $\Delta \mathbb{E}_{t+1}$ denotes a change in the expectations operator defined by $\Delta \mathbb{E}_{t+1}=\mathbb{E}_{t+1}-\mathbb{E}_{t}$. This equation means that consumption between periods $t$ and $t+1$ changes only if changes in the permanent income are recognized by consumers.

By the fundamental balance-of-payments identity, the current account $C A_{t}$ equals changes in the country's net foreign assets (i.e., $C A_{t} \equiv A_{t+1}-A_{t}$ ). Therefore, using (1) and (2), we have

$$
C A_{t}=X_{t}-X_{t}^{p}=-\sum_{j=1}^{\infty}(1+r)^{-j} \mathbb{E}_{t} \Delta X_{t+j},
$$

meaning that the current account is minus the present discounted value of future expected changes in the net output.

It is straightforward to extend this standard RE model with imperfect capital mobility. Shibata and Shintani (1998) consider consumers with limited access to the international capital market, as in Campbell and Mankiw (1989, 1990). A fraction $1-\lambda$ of consumers have perfect access to international capital markets and their consumption is determined by (2). The remaining fraction $\lambda \in[0,1)$ of consumers hold neither international financial assets nor liabilities: They are hand-to-mouth consumers who consume all endowment within a single period. When we introduce the hand-to-mouth consumer into the RE model, we call this model the hybrid RE model. Denoting the aggregate consumption in the hybrid model 
by $C_{t}^{H Y}$, we express $C_{t}^{H Y}=(1-\lambda) C_{t}+\lambda X_{t}$. Likewise, let $C A_{t}^{H Y}$ be the current account in the hybrid model. Because hand-to-mouth consumers do not hold international financial assets, $C A_{t}^{H Y}$ becomes

$$
C A_{t}^{H Y}=(1-\lambda) C A_{t}
$$

This implies that the magnitude of the current account changes is small compared to the case of perfect capital mobility described by (3). We thus call $\lambda$ the degree of imperfect capital mobility.

\subsection{Characterizing the RE models}

We characterize the pure and hybrid RE models using (3) and (4). We look at theoretical predictions for the persistence and volatility of the current account under the assumption of $\operatorname{AR}(1)$ process of the net output growth.

Let $g_{t} \equiv \ln \left(X_{t} / X_{t-1}\right)$ be the net output growth. Assume that $g_{t}=(1-\phi) \mu+\phi g_{t-1}+\varepsilon_{t}$, where $\varepsilon_{t} \sim$ i.i.d. $\left(0, \sigma^{2}\right)$ and $|\phi|<1$. As discussed in Campbell and Deaton (1989), this assumption of the stationary net output growth rate requires some reformulation of variables. In particular, to ensure the stationarity of the current account, we divide both sides of (3) by $X_{t}$. We obtain $c a_{t} \equiv C A_{t} / X_{t}=-\sum_{j=1}^{\infty}(1+r)^{-j} \mathbb{E}_{t}\left(\Delta X_{t+j} / X_{t}\right)$. While we will evaluate the model with $\mu \neq 0$ in Section 5 , we temporarily set $\mu=0$ only for expositional purposes. In this case, the first-order approximation of $c a_{t}$ yields

$$
c a_{t} \simeq-\sum_{j=1}^{\infty}(1+r)^{-j} \mathbb{E}_{t} g_{t+j}=-\frac{\phi}{1+r-\phi} g_{t} .
$$

The left column of Table 2 summarizes the characterization of the RE model's predictions. The proportionality of $c a_{t}$ to $g_{t}$ in (5) implies that the persistence of $c a_{t}$ should be the same as that of $g_{t}$, namely, $\rho_{c a}=\phi$. It also implies that the predicted volatility is given by $V_{c a}=$ $s d\left(c a_{t}\right) / s d\left(g_{t}\right)=\phi /(1+r-\phi)$. From Hall's random walk hypothesis, it is evident that changes in consumption are serially uncorrelated in the RE model. In our case with reformulation of variables, we define $\Delta c_{t+1} \equiv \Delta C_{t+1} / X_{t}$. These newly defined (normalized) changes in consumption can be expressed as $\Delta c_{t+1}=\Delta \mathbb{E}_{t+1}\left(X_{t+1}^{p} / X_{t}\right) \simeq[(1+r) /(1+r-\phi)] \varepsilon_{t+1}$ by the first-order approximation. Since $\varepsilon_{t}$ is independent and identically distributed, the predicted persistence of changes in consumption is zero, namely, $\rho_{\Delta c}=0$.

These predictions of the pure RE model are inconsistent with the evidence in Section 2. While the model predicts that $\rho_{c a}=\phi$, the data suggests that $\rho_{c a}^{\text {data }}>\phi^{\text {data }}$, as indicated in Table 1. It also fails to explain the volatility of the current account, if we recall $V_{c a}^{\text {data }} \simeq 2$. 
For the pure RE model to generate $V_{c a} \simeq 2$, taking the world interest rate $r$ as given, it requires a sufficiently large value of $\phi$. For example, if $r=0.04, \phi$ needs to be as large as 0.69 , as opposed to the data of $\phi^{\text {data }}=0.16 .{ }^{14}$ Note also that serially uncorrelated changes in consumption, $\rho_{\Delta c}=0$, is against the data, $\rho_{\Delta c}^{\text {data }}>0$.

The hybrid RE model can generate better predictions for the persistence of changes in consumption (see the right column of Table 2). Again, denoting $\Delta c_{t+1}^{H Y} \equiv \Delta C_{t+1}^{H Y} / X_{t}$, we have $\Delta c_{t+1}^{H Y} \simeq(1-\lambda) \Delta c_{t+1}+\lambda g_{t+1}$ in the hybrid RE model. Since $g_{t+1}$ is serially correlated, the assumption of imperfect capital mobility leads to predictable changes in consumption. The resulting $\rho_{\Delta c}^{H Y}$ takes a form of $\rho_{\Delta c}^{H Y}=\Lambda_{0} \phi \neq 0$, where $\Lambda_{0}$ is a function of $\lambda$ and the second moments of $\Delta c_{t}$ and $g_{t}$ (see the footnote of Table 2 for the analytical expression). The improvement can be made at least without influencing the predicted persistence of the current account. Because $C A_{t}^{H Y}=(1-\lambda) C A_{t}$ from (4), $c a_{t}^{H Y}=(1-\lambda) c a_{t}=-(1-\lambda) \phi /(1+r-\phi) g_{t}$, where $c a_{t}^{H Y} \equiv C A_{t}^{H Y} / X_{t}$. The proportionality of $c a_{t}^{H Y}$ to $c a_{t}$ means that the first-order autocorrelation of $c a_{t}^{H Y}$ is unchanged in comparison to the pure RE model: $\rho_{c a}^{H Y}=\rho_{c a}=\phi$.

However, the better prediction for the persistence of changes in consumption is achieved at the cost of undermining the predicted volatility of the current account. The above proportionality also implies that $V_{c a}^{H Y}=(1-\lambda) V_{c a}$, where $V_{c a}^{H Y} \equiv s d\left(c a_{t}^{H Y}\right) / s d\left(g_{t}\right)$. Since $\lambda \in[0,1)$, the volatility of $c a_{t}^{H Y}$ is dampened by $\lambda$. Therefore, for the hybrid RE model to generate $V_{c a} \simeq 2$, the hybrid model needs an even larger value of $\phi$ than the pure RE model. For example, if $r=0.04$ and $\lambda=0.50$, the hybrid $\mathrm{RE}$ model requires that $\phi=0.83$, which is larger than 0.69 required in the pure $\mathrm{RE}$ model. ${ }^{15}$

\section{The SI models}

To improve predictions of the ICA model, we replace RE in the ICA model with SI. In this section, we leave the detailed maximization problem of the SI model to Appendix A.1 and focus on how the current account dynamics are described in the SI model.

\subsection{Setup}

Let us assume that, in every period, only randomly selected $1-\omega$ fraction of consumers update their information set and that the remaining fraction $\omega \in[0,1)$ of consumers do not

\footnotetext{
${ }^{14}$ Solving $V_{c a} \simeq 2=\phi /(1+r-\phi)$ for $\phi$ yields $\phi \simeq 2(1+r) / 3$. When $r=0.04$, $\phi$ turns to be 0.69 .

${ }^{15}$ Solving $V_{c a}^{H Y} \simeq 2=(1-\lambda) \phi /(1+r-\phi)$ for $\phi$ yields $\phi=2(1+r) /(3-\lambda)$. If we evaluate it at $r=0.04$ and $\lambda=0.50, \phi \simeq 0.83$.
} 
update their information set. We call $\omega$ the degree of information rigidity. Our assumption simplifies the SI model of consumption by Reis (2006), who considers endogenous infrequent information updating. ${ }^{16}$ Despite the simplification, as we will later show, the model predictions are very similar to Reis (2006).

Given infrequently updated information, consumers make decisions as rationally as they can. Suppose that a consumer updated his information in period $t$ and does not obtain new information in $t+1$. In this case, he does not change his consumption in period $t+1$ since he recognizes no changes in the permanent income. He sticks to a consumption plan that he could make in period $t$. Therefore, if the information is not updated in period $t+1$, any shock in period $t+1$ is unrecognized and absorbed by the consumer's saving. Reis (2006) refers to consumers who stick to their consumption plans as inattentive consumers.

More formally, an inattentive consumer who has period- $t$ information chooses the ex ante optimal plan of consumption $\left\{C_{t+j, j}\right\}_{j=0}^{\infty}$, where $C_{t+j, j}$ is consumption chosen for period $t+j$ with $j$-period delay of information. Note that $C_{t, 0}$ represents consumption that the consumer enjoys in period $t$ with full information. This $C_{t, 0}$ must be the same as the optimal consumption under the RE model. If the consumer does not receive new information until period $t+j$, the consumer chooses $C_{t+j, j}$ that was planned in period $t$. Note also that $C_{t+j, j}=C_{t, 0}$ is satisfied because the inattentive consumer perceives no changes in his permanent income. Therefore, for $j=1,2, \ldots$, we have

$$
C_{t+j, j}=C_{t, 0}=r A_{t}+X_{t}^{p}
$$

Let $S_{t+j, j}$ be changes in the foreign asset holdings of the consumer in period $t+j$, conditional that his information was updated in period $t$ but has not been updated until period $t+j$. Then, $S_{t+j, j}$ is given by

$$
S_{t+j, j}=r A_{t+j}+X_{t+j}-C_{t+j, j}
$$

where $A_{t+j}$ follows (1) evaluated at $C_{t+j}=C_{t+j, j}$. That is, $A_{t+j+1}=(1+r) A_{t+j}+X_{t+j}-$ $C_{t+j, j}$.

While $S_{t+j, j}$ in (7) looks similar to the current account in the RE model, they need to be distinguished in two aspects. First, $S_{t+j, j}$ absorbs all changes in endowment between $t$ and $t+j$, together with returns of the unintended change in the foreign asset holdings. Using

\footnotetext{
${ }^{16}$ In Reis (2006), consumers face the cost of obtaining and processing information and decide whether to update their information and recompute the optimal consumption plan. In our setting, the information updating is exogenously given.
} 
(6), we can rewrite $S_{t+j, j}$ as

$$
\begin{aligned}
S_{t+j, j} & =r\left(A_{t+j}-A_{t}\right)+X_{t+j}-X_{t}^{p} \\
& =r\left(\Delta A_{t+j}+\ldots+\Delta A_{t+1}\right)+\Delta X_{t+j}+\ldots+\Delta X_{t+1}+S_{t, 0}, \text { for } j=0,1,2, \ldots,
\end{aligned}
$$

where $S_{t, 0}=X_{t}-X_{t}^{p}$ which equals the current account under the RE model. Under SI, the inattentive consumer's consumption $\left(C_{t+j, j}\right)$ does not respond to the unrecognized changes in endowment between periods $t$ and $t+j$. In (8), saving absorbs all unrecognized changes in endowment $\Delta X_{t+1}, \Delta X_{t+2}, \ldots, \Delta X_{t+j}$. Accordingly, changes in the inattentive consumer's foreign asset holdings also include returns from the unrecognized changes in endowment (i.e., $\left.r\left(\Delta A_{t+j}+\ldots+\Delta A_{t+1}\right)\right)$. We rewrite (8) recursively as ${ }^{17}$

$$
S_{t+j, j}=(1+r) S_{t+j-1, j-1}+\Delta X_{t+j} \text { for } j=1,2,3, \ldots
$$

The second aspect that should be distinguished from the current account in the RE model is that changes in foreign asset holdings differ across inattentive consumers, depending on how they update their information. To obtain the current account in the SI model, we need to aggregate individual foreign asset holdings across all inattentive consumers. Based on the assumption of information updating, the current account in the SI model is

$$
C A_{t}=(1-\omega) \sum_{k=0}^{\infty} \omega^{k} S_{t, k}
$$

where $S_{t, k}$ is the period- $t$ changes in the inattentive consumer's foreign assets based on the information in period $t-k$. Using $(9), S_{t, k}$ can also be written as

$$
S_{t, k}=(1+r) S_{t-1, k-1}+\Delta X_{t},
$$

where $S_{t-k, 0}=X_{t-k}-X_{t-k}^{p}$.

It is again straightforward to extend the SI model with imperfect capital mobility. The aggregate consumption is given by $C_{t}^{H Y}=(1-\lambda) C_{t}+\lambda X_{t}$ and the current account is given by

$$
C A_{t}^{H Y}=(1-\lambda) C A_{t}
$$

in the hybrid SI model so that (4) continues to hold. ${ }^{18}$

\footnotetext{
${ }^{17}$ See Appendix A.2.

${ }^{18}$ Reis (2006) also provides the microfoundation for (12). In particular, consumers may stick to saving plans and let their consumption respond to unrecognized shocks to endowment, instead of sticking to consumption
} 


\subsection{Characterizing the SI models}

We characterize the SI and the hybrid SI models using (10) - (12). We establish propositions for the current account and changes in consumption under the pure SI model. We then discuss the hybrid SI model.

\subsubsection{Persistence and volatility of the current account}

The following proposition describes current account dynamics under the pure SI model:

Proposition 1 Suppose that inattentive consumers update their information with the probability of $1-\omega$ every period. Suppose also that the degree of information rigidity $\omega$ is sufficiently low such that $\omega(1+r)<1$. Then, the current account is given by

$$
C A_{t}=\omega^{*} C A_{t-1}+(1-\omega) S_{t, 0}+\omega \Delta X_{t}
$$

where $S_{t, 0}=X_{t}-X_{t}^{p}$ and $\omega^{*}=\omega(1+r)$.

Furthermore, suppose that the net output growth follows a covariance-stationary AR(1) process with mean zero: $g_{t}=\phi g_{t-1}+\varepsilon_{t}$, where $\varepsilon_{t} \sim$ i.i.d. $\left(0, \sigma^{2}\right)$. Then, ca $a_{t}$ can be approximated by the $A R(2)$ process:

$$
c a_{t}=\left(\omega^{*}+\phi\right) c a_{t-1}-\left(\omega^{*} \phi\right) c a_{t-2}+\frac{\omega^{*}-\phi}{1+r-\phi} \varepsilon_{t} .
$$

Proof: See the Appendix A.3.

The first part of Proposition 1 tells us that the current account is written as the first-order difference equation with the two driving forces. The first driving force is $S_{t, 0}$, changes in foreign asset holdings under full information. The impact of $S_{t, 0}$ becomes weaker as $\omega$ becomes higher. The second driving force is $\Delta X_{t}$. A fraction $\omega$ of inattentive consumers with old information let their saving absorb unrecognized shocks to endowment. For this reason, $\Delta X_{t}$ appears in (13) with its coefficient $\omega$. Also, recall that the effect of unrecognized changes in endowment on $C A_{t}$ is carried over to the subsequent periods with interest earnings. Therefore,

plans and letting their saving respond to shocks. He refers to such consumers as inattentive savers. Reis (2006) shows that, if the costs of planning are not too small, it is optimal for inattentive savers not to re-plan their savings at all. This result suggests that inattentive savers behave like consumers without any access to the international capital market, since their consumption is perfectly correlated with endowment. If the initial assets of inattentive savers are zero, the presence of inattentive savers reproduces the same equation as (12). 
as $\omega^{*}=\omega(1+r)$ increases, the coefficient on $C A_{t-1}$ becomes larger, making $C A_{t}$ more persistent. Turning to the second part of the proposition, $c a_{t}$ follows the $\operatorname{AR}(2)$ process, generalizing (5) in the RE model. Indeed, substituting $\omega^{*}=\omega(1+r)=0$ in (13) results in the $\operatorname{AR}(1)$ process $c a_{t}=\phi c a_{t-1}-\phi /(1+r-\phi) \varepsilon_{t}$. Comparing $c a_{t}=-\phi /(1+r-\phi) \sum_{j=0}^{\infty} \phi^{j} \varepsilon_{t-j}$ with $g_{t}=\sum_{j=0}^{\infty} \phi^{j} \varepsilon_{t-j}$ implies $c a_{t}=-\phi /(1+r-\phi) g_{t}$, reproducing (5).

The persistence of $c a_{t}$ is now increasing in $\omega^{*}$ so that the pure SI model can generate a persistent current account even when net output growth is not persistent. In particular, the first-order autocorrelation of $c a_{t}$ is calculated as $\left(\omega^{*}+\phi\right) /\left(1+\omega^{*} \phi\right)$ from (14) as long as $\omega^{*} \neq \phi$. The left panel of Figure 1 shows the first-order autocorrelation of the current account against $\omega .^{19}$ The blue line is the persistence under $\phi=0.20$, while the red line is that under $\phi=0.80$. We reconfirm that persistence of the current account increases with $\omega$, regardless of the value of $\phi$, except for the case of $\omega^{*}=\phi$. If $\omega^{*}$ happens to equal $\phi$, the coefficient on $\varepsilon_{t}$ is zero in (14) and the current account is constant for all $t$. Our result on the persistence of the current account can be summarized in the next corollary:

Corollary 1 Under the pure SI model with $\mu=0$, the first-order autocorrelation of the current account $\mathrm{ca}_{t}$ is given by

$$
\rho_{c a}=\frac{\omega^{*}+\phi}{1+\omega^{*} \phi}
$$

and is always greater than $\rho_{c a}=\phi$ under the pure RE model, as long as $\omega^{*} \neq \phi$.

We move on to volatility of the current account in the SI model. Equation (14) implies the following corollary:

Corollary 2 Under the pure SI model with $\mu=0$, the volatility of the current account $V_{c a}=s d\left(c a_{t}\right) / s d\left(g_{t}\right)$ is given by

$$
V_{c a}=\sqrt{\frac{1+\omega^{*} \phi}{\left(1-\omega^{*} \phi\right)\left[1-\left(\omega^{*}\right)^{2}\right]}} \sqrt{\frac{\left(\omega^{*}-\phi\right)^{2}}{(1+r-\phi)^{2}}} .
$$

The middle panel of Figure 1 plots the volatility against $\omega$. The volatility decreases with $\omega$ if $\omega^{*}<\phi$ and increases with $\omega$ if $\omega^{*}>\phi$. When $\phi=0.20$, the volatility increases with $\omega$ over a wide range of $\omega$. Therefore, even when $\phi$ takes a low value as in the data, the SI model can generate a volatile current account with a large value of $\omega$. By contrast, as shown in the red line, when $\phi=0.80$, the volatility increases with $\omega$ over a very narrow range of $\omega$.

\footnotetext{
${ }^{19}$ Here, we set $r=0.04$ to plot the curves. We also choose the range of $\omega \in[0,0.96]$, which ensures the stationarity of the current account.
} 


\subsubsection{Persistence of consumption growth}

It is worthwhile discussing persistent changes in consumption in the SI model. Using the model with endogenous infrequent information updating, Reis (2006) demonstrates that his SI model of consumption can successfully generate predictable changes in consumption. We confirm persistent changes in consumption under exogenous infrequent information updating. In the next proposition, we analytically derive the stochastic process of $\Delta c_{t+1}$ :

Proposition 2 Suppose that inattentive consumers update their information with the probability of $1-\omega$ every period. Suppose also that the degree of information rigidity $\omega$ is sufficiently low such that $\omega(1+r)<1$. Then, changes in the consumption are given by

$$
\Delta C_{t+1}=\omega^{*} \Delta C_{t}+(1-\omega) \Delta \mathbb{E}_{t+1} X_{t+1}^{p} .
$$

Furthermore, suppose that net output growth follows a covariance-stationary AR(1) process with mean zero: $g_{t}=\phi g_{t-1}+\varepsilon_{t}$, where $\varepsilon_{t} \sim$ i.i.d. $\left(0, \sigma^{2}\right)$. Then, $\Delta c_{t+1}$ can be approximated by the $A R(1)$ process:

$$
\Delta c_{t+1}=\omega^{*} \Delta c_{t}+(1-\omega) \frac{1+r}{1+r-\phi} \varepsilon_{t+1} .
$$

Proof: See the Appendix A.4.

As is clear in (18), the persistence of changes in consumption critically depends on $\omega^{*}$. In the right panel of Figure 1, we plot the first-order autocorrelation of $\Delta c_{t}$. It has a one-to-one relationship with $\omega$. For example, when $\omega=0.80$ and $r=0.04, \rho_{\Delta c}=(1+r) \omega=0.83$. We summarize this result in the following corollary:

Corollary 3 Under the pure SI model with $\mu=0$, the first-order autocorrelation of $\Delta c_{t}$ is given by $\rho_{\Delta c}=\omega^{*}$, and is always greater than $\rho_{\Delta c}=0$ under the pure $R E$ model.

We have two additional remarks on changes in consumption. First, not surprisingly, the dynamic properties of changes in consumption are very close to those in Reis (2006). His proposition 2 states that, when the maximum length of time during which consumers are inattentive is $q$ periods, changes in consumption follow the $\mathrm{MA}(q)$ process with monotonically decreasing MA coefficients. In our SI model, the maximum length of time of being inattentive is infinity and the $\mathrm{MA}(\infty)$ representation of the $\mathrm{AR}(1)$ process (18) implies that MA coefficients are exponentially decaying. 
Second, as Reis (2006) argues, the representative-agent habit formation model can be an alternative explanation for persistent changes in consumption. It can be shown analytically that the current account in the habit formation model is the observational equivalent to the current account in the SI model. In particular, if the period utility in the habit formation model is given by $u\left(C_{t}-\gamma C_{t-1}\right)$ and the habit parameter $\gamma$ is equal to $\omega^{*}$, the current account in the habit formation model follows the same stochastic process as that in our SI model. Therefore, the two models are indistinguishable in the aggregate data. ${ }^{20}$ In the micro data, however, there are mixed evidence for the presence of habit formation. ${ }^{21}$ In addition, while the structure of SI models suggest disagreements about expectations, some empirical studies based on the micro survey data support such disagreements about expectations on main economic variables. For example, Dovern, Fritsche, and Slacalek (2012) report disagreement among professionals for main economic indicators including GDP growth in G7 countries. Mankiw, Reis, and Wolfers (2003) and Coibion, Gorodnichenko, and Kumar (2018) find much stronger disagreement among economic agents such as households and firms than among professional forecasters. While Gruber (2004) finds that the representative-agent habit formation model performs better than the model without habits in predicting the current account dynamics, the better performance of his model may also reflect the presence of SI. An advantage of our SI model is that the explanation based on SI is broadly in line with the above evidence from the micro data.

\subsubsection{Impulse responses}

To better understand the current account in the SI model, it is helpful to investigate the impulse response functions. Figure 2 plots the impulse response functions of $g_{t}, c a_{t}$, and $\Delta c_{t}$ to one unit increase in $\varepsilon_{t}$. The leftmost panel points to the impulse response of $g_{t}$. Here we set $\phi$ at 0.20 , so the response of $g_{t}$ decays quickly. In the middle and right panels, we compare the response of $c a_{t}$ and $\Delta c_{t}$ under the RE model $(\omega=0)$ and the SI model $(\omega=0.20$ or $0.80)$.

Let us first consider the impulse response functions of $c a_{t}$ and $\Delta c_{t}$ under the RE model $(\omega=0)$. As shown in the blue line in the middle panel of Figure 2, the current account declines in response to $\varepsilon_{t}$. Because the shock has a positive permanent effect on endowment, consumers' permanent income increases more than the current endowment. In this case, increases in consumption at the impact period are larger than those in endowment at the

\footnotetext{
${ }^{20}$ See also Carroll, Slacalek, and Sommer (2011) for the similarity between the habit formation model and their "sticky expectations" model.

${ }^{21}$ For example, see Dynan (2000) and Guariglia and Rossi (2002) among others.
} 
same period. As a result, the economy runs current account deficits.

How do the impulse responses differ in the SI model $(\omega>0)$ ? When $\omega=0.20$, the current account is nearly constant, as the coefficient on $\varepsilon_{t}$ in (14) is close to zero. To perceive the intuition, recall that inattentive consumers let their saving absorb unrecognized shocks between periods of planning. Even though a permanent effect on endowment increases the permanent income of all consumers, some consumers do not reduce their saving. Instead, they unintentionally increase their foreign asset holdings. The unintended increases in foreign asset holdings offset reductions in foreign asset holdings resulting from a permanent shock to endowment.

If the degree of information rigidity is sufficiently high (e.g., $\omega=0.8$ ), the current account increases. In response to a positive shock $\varepsilon_{t}$, unintended increases in foreign asset holdings exceed decreases in foreign asset holdings. In this case, the increases in consumption are smaller than those in endowment at the impact period. As a result, the economy runs the current account surplus.

\subsubsection{The hybrid SI model}

Figure 3 plots the persistence and volatility of the current account and the persistence of changes in consumption against $\omega$ under the pure and hybrid SI models. In the figure, we set $\lambda=0.50$ for the hybrid SI model. The value is borrowed from the simple average of estimates in Shibata and Shintani (1998) who estimate $\lambda$ of 11 developed countries.

The proportionality of $c a_{t}^{H Y}$ to $c a_{t}$ is fully preserved in the hybrid SI model. The relationship of $\rho_{c a}^{H Y}=\rho_{c a}$ continues to hold in the hybrid SI model, and the curve for $\rho_{c a}^{H Y}$ traces out the upward-sloping curve for $\rho_{c a}$ in the left panel of Figure 3. Therefore, $\rho_{c a}^{H Y}$ can also be high under information rigidity. This result is summarized in the following corollary:

Corollary 4 Under the hybrid SI model with $\mu=0$, the first-order autocorrelation of the current account $c a_{t}^{H Y}$ is given by $\rho_{c a}^{H Y}=\left(\omega^{*}+\phi\right) /\left(1+\omega^{*} \phi\right)$ and is the same as that under the pure SI model.

Turning to the volatility of the current account, the proportionality of $c a_{t}^{H Y}$ to $c a_{t}$ continues to imply that $V_{c a}^{H Y}=(1-\lambda) V_{c a}$. The dashed line corresponds to the hybrid SI model with $\lambda=0.50$, while the solid line points to the pure SI model (i.e., $\lambda=0$ ). The dashed line in the middle panel of Figure 3 indicates that the volatility of the current account in the hybrid SI model is reduced in comparison to the solid line. However, $V_{c a}$ on the right-hand side can increase with $\omega$ as long as $\omega \in(\phi /(1+r), 1)$, as in the case of the pure SI model. 
When $\phi$ takes a low value and $\omega$ is sufficiently large, the current account can be volatile in the hybrid SI model. The analytical expression for $V_{c a}^{H Y}$ is provided by the following corollary:

Corollary 5 Under the hybrid SI model with $\mu=0$, the volatility of the current account $V_{c a}^{H Y}=s d\left(c a_{t}^{H Y}\right) / s d\left(g_{t}\right)$ is given by

$$
V_{c a}^{H Y}=(1-\lambda) V_{c a}=(1-\lambda) \sqrt{\frac{1+\omega^{*} \phi}{\left(1-\omega^{*} \phi\right)\left[1-\left(\omega^{*}\right)^{2}\right]}} \sqrt{\frac{\left(\omega^{*}-\phi\right)^{2}}{(1+r-\phi)^{2}}} .
$$

How can we describe the persistence of changes in the aggregate consumption in the hybrid SI model? Recall that changes in the aggregate consumption $\Delta c_{t+1}^{H Y}$ is a convex combination of $\Delta c_{t+1}$ and $g_{t+1}$. We demonstrate that persistence of changes in the aggregate consumption is a weighted average of persistence of $\Delta c_{t}$ and $g_{t}$, that is, $\omega^{*}$ and $\phi$. The analytical expression for the persistence of changes in consumption in the hybrid SI model is summarized by the following corollary:

Corollary 6 Under the hybrid SI model with $\mu=0$, the first-order autocorrelation of $\Delta c_{t}$ is given by the weighted average of $\omega^{*}$ and $\phi$ :

$$
\rho_{\Delta c}^{H Y}=(1-\Lambda) \omega^{*}+\Lambda \phi
$$

where $\Lambda \in[0,1]$ is a weight given by

$$
\begin{aligned}
\Lambda & =\Lambda(\lambda, \phi, \omega) \\
& =\frac{\lambda^{2} \operatorname{Var}\left(g_{t}\right)+\lambda(1-\lambda) \operatorname{Cov}\left(g_{t}, \Delta c_{t}\right)}{(1-\lambda)^{2} \operatorname{Var}\left(\Delta c_{t}\right)+2 \lambda(1-\lambda) \operatorname{Cov}\left(g_{t}, \Delta c_{t}\right)+\lambda^{2} \operatorname{Var}\left(g_{t}\right)} .
\end{aligned}
$$

Proof: See the Appendix A.5.

The persistence of changes in the aggregate consumption in the hybrid SI model no longer has a one-to-one relationship with $\omega$. The extreme right panel of Figure 3 plots the persistence of changes in the aggregate consumption in the pure and the hybrid SI models. When $\omega$ is low, the dashed line is located above the solid line, increasing the overall persistence of changes in the aggregate consumption by means of the persistence of net output growth. When $\omega$ is large, the dashed line is located below the solid line, preventing the overall persistence from increasing. ${ }^{22}$ In other words, imperfect capital mobility breaks the tight link

\footnotetext{
${ }^{22}$ The dashed line in the right panel of Figure 3 also shows that the persistence of changes in the aggregate
} 
between the persistence of changes in consumption and the degree of information rigidity.

\section{Assessment of the SI models}

This section assesses the SI models in comparison to the RE models.

\subsection{Methodology}

We begin by slightly generalizing the pure SI model with the possibility of the non-zero mean growth rate of $g_{t}$, i.e., $\mu \neq 0$. While this generalization does not affect the steady state of $\Delta c_{t}$, the steady state value of $c a_{t}$ is no longer zero. ${ }^{23}$ To address the non-zero steady state, it would be convenient to define $c \hat{a}_{t}$ and $\hat{g}_{t}$ by $c \hat{a}_{t} \equiv c a_{t}-\mathbb{E}\left(c a_{t}\right)$ and $\hat{g}_{t} \equiv g_{t}-\mu$, respectively. The following proposition generalizes the second part of Propositions 1 and 2:

Proposition 3 Suppose that information rigidity is present as in Propositions 1 and 2. Suppose also that net output growth follows a covariance-stationary $A R(1)$ process with nonzero mean: $g_{t}=(1-\phi) \mu+\phi g_{t-1}+\varepsilon_{t}$, where $\varepsilon_{t} \sim$ i.i.d. $\left(0, \sigma^{2}\right)$. Assume that $\mu$ and $\omega$ are both sufficiently low such that $\mu<r$ and $\omega_{\mu}^{*} \equiv \omega(1+r) /(1+\mu)<1$. The stochastic process of $c \hat{a}_{t}$ and $\Delta c_{t+1}$ can be approximated by

$$
c \hat{a}_{t}=\left(\omega_{\mu}^{*}+\phi\right) c \hat{a}_{t-1}-\left(\omega_{\mu}^{*} \phi\right) c \hat{a}_{t-2}+\frac{r}{r-\mu} \frac{\omega_{\mu}^{*}-\phi}{(1+r) /(1+\mu)-\phi} \varepsilon_{t},
$$

and

$$
\Delta c_{t+1}=\omega_{\mu}^{*} \Delta c_{t}+(1-\omega) \frac{r}{r-\mu} \frac{(1+r)(1+\mu)}{1+r-\phi(1+\mu)} \varepsilon_{t+1}
$$

respectively.

Proof: See the Appendix A.6.

Here we impose a restriction that the net output grows at a slower rate $\mu$ than the foreign asset holdings: $\mu<r$. We require this assumption to ensure the stationarity of the non-financial permanent income scaled by the net output. ${ }^{24}$ A positive $\mu$ slightly decreases

consumption decreases with $\omega$, even though an increase in $\omega$ generally raises the persistence of $\Delta c_{t}$, which is included in $\Delta c_{t}^{H Y}$. The decline occurs because the weight $\Lambda$ in (20) increases as $\omega \rightarrow 1$.

${ }^{23}$ See (34) in Appendix A.3.2. If the net output has a positive deterministic trend, the economy is sustainable under the current account deficit in the steady state.

${ }^{24}$ To understand the stationarity, consider the non-financial permanent income scaled by the net output, $X_{t}^{p} / X_{t}=r /(1+r) \sum_{j=0}^{\infty}(1+r)^{-j} \mathbb{E}_{t}\left(X_{t+j} / X_{t}\right)=r /(1+r)+$ $r /(1+r) \sum_{j=1}^{\infty}(1+r)^{-j} \mathbb{E}_{t}\left[\exp \left(\sum_{k=1}^{j} g_{t+k}\right)\right]$. In the nonstochastic steady state, the non-financial 
the persistence of the current account and consumption growth, since a higher $\mu$ negatively influences $\omega_{\mu}^{*}$. Obviously, these results are applicable to the RE models and can be extended to the hybrid SI model.

Before we discuss the performance of the SI models, let us quickly reconfirm the poor performance of the RE models under nonzero $\mu$. Table 3 summarizes predictions of the pure and hybrid RE models for the theoretical moments. The left panel reports the predictions of the pure RE model. They are inconsistent with the actual moments (shown in the most right panel) even if nonzero $\mu$ is taken into account. The predicted persistence of the current account is 0.16 on the cross-country average, which is much lower than the observed persistence of 0.82 . The predicted volatility is 0.44 on average, again much lower than the data of 2.29. Of course, changes in consumption have no persistence under $\lambda=0$.

The poor performance can also be reconfirmed under $\lambda=0.5$. As we discussed in Section 3, the hybrid RE model can generate serially correlated changes in consumption at the cost of undermining the predicted volatility of the current account. While the persistence of changes in consumption is slightly positive (0.05 on average) due to imperfect capital mobility, the predicted volatility of the current account is reduced from 0.44 in the pure RE model to 0.22 in the hybrid RE model.

To assess the SI models, we estimate $\omega$ and $\lambda$ using the data of 16 developed OECD countries listed in Table 1, rather than using pre-specified values of $\omega$ and $\lambda$. We obtain $\omega$ and $\lambda$ to match the theoretical moments of the persistence and volatility of the current account and the persistence of changes in consumption with the sample moments in each country. Let $f(\theta)$ be a vector of distances between the theoretical and sample moments for the persistence and volatility of the current account and the persistence of changes in consumption, where $\theta$ denotes the vector of parameter consisting of $\omega$ and $\lambda$. In the case of the hybrid SI model, for example, $f(\theta)=\left[\rho_{c a}^{H Y}(\theta)-\rho_{c a}^{\text {data }}, V_{c a}^{H Y}(\theta)-V_{c a}^{\text {data }}, \rho_{\Delta c}^{H Y}(\theta)-\rho_{\Delta c}^{\text {data }}\right]^{\prime}$. Using the data of $c a_{t}$ and $\Delta c_{t}$ in each country, we obtain the weighting matrix $\hat{W}$ from the inverse of the bootstrap covariance matrix of $\left(\rho_{c a}^{\text {data }}, V_{c a}^{\text {data }}, \rho_{\Delta c}^{\text {data }}\right)^{\prime} \cdot{ }^{25}$ The objective function $Q(\theta)$ to be minimized is defined by the quadratic form:

$$
Q(\theta)=f(\theta)^{\prime} \hat{W} f(\theta)
$$

When minimizing $Q(\theta)$, we impose the restriction that $\omega \in[0,(1+\mu) /(1+r))$ to ensure permanent income scaled by the net output reduces to $r /(1+r) \sum_{j=0}^{\infty}[(1+\mu) /(1+r)]^{j}$. For this expression to be non-explosive, $\mu$ must be lower than $r$. See also Campbell and Deaton (1989).

${ }^{25} \mathrm{~A}$ block bootstrap method with a block length of four is employed to compute the bootstrap covariance matrix . 
that $\omega_{\mu}^{*}<1$ for both of the pure and hybrid SI models. We further impose the restriction that $\lambda=0$ in the pure SI model and $\lambda \in[0,1)$ in the hybrid SI model, respectively. The minimizers of $Q(\theta)$ are denoted by $\tilde{\theta}=(\tilde{\omega}, 0)^{\prime}$ for the former and $\hat{\theta}=(\hat{\omega}, \hat{\lambda})^{\prime}$ for the latter, respectively.

\subsection{Predictions of the SI models}

The left panel of Table 4 shows the predictions of the pure SI model and the middle panel presents those of the hybrid SI model. The two models' predictions are based on our estimates of $\omega$ and $\lambda$, which we will discuss in the next section. For comparison, the right panel again reports the actual moments from the OECD countries.

Let us first consider the pure SI model. Overall, it exhibits a great improvement in comparison to the RE models in Table 3. For example, the pure SI model can almost fully account for the three targeted moments in the Netherlands. In particular, the predicted moments are $\left(\rho_{c a}, V_{c a}, \rho_{\Delta c}\right)=(0.83,2.05,0.76)$, as opposed to the actual moments: $\left(\rho_{c a}^{\text {data }}, V_{c a}^{\text {data }}, \rho_{\Delta c}^{\text {data }}\right)=(0.85,2.07,0.74)$. The SI model also performs well in other countries, though all moments are not fully explained. For example, the predicted moments in Denmark are $\left(\rho_{c a}, V_{c a}, \rho_{\Delta c}\right)=(0.77,1.75,0.78)$, while the actual moments are $(0.94,3.73,0.20)$. This outcome is a remarkable improvement in predictions relative to the RE models, because the RE models predict $\left(\rho_{c a}, V_{c a}, \rho_{\Delta c}\right)=(-0.01,0.02,0.00)$ and $\left(\rho_{c a}^{H Y}, V_{c a}^{H Y}, \rho_{\Delta c}^{H Y}\right)=$ $(-0.01,0.01,0.01)$.

While the pure SI model remarkably improves predictions of the current account, it tends to overpredict the persistence of changes in consumption. In particular, $\rho_{\Delta c}$ is 0.65 in the cross-country average but the actual persistence is only 0.25 , which is much lower than in the model. The overprediction stems from the one-to-one relationship of $\rho_{\Delta c}=$ $\omega_{\mu}^{*}=\omega(1+r) /(1+\mu)$ in (23). That is, although a large $\omega$ helps the SI model explain the persistence and volatility of the current account, the one-to-one relationship between $\rho_{\Delta c}$ and $\omega$ also increases the persistence of changes in consumption far beyond the observed persistence.

The hybrid SI model breaks the tight link. The middle panel of Table 4 presents the theoretical moments generated by the hybrid SI model. The hybrid SI model continues to predict a persistent and volatile current account but now with a moderate degree of persistent consumption growth. In the example of Denmark, the prediction of the hybrid SI model is $\left(\rho_{c a}^{H Y}, V_{c a}^{H Y}, \rho_{\Delta c}^{H Y}\right)=(0.98,3.83,0.21)$ as opposed to the data of $(0.94,3.73,0.20)$. In terms of the cross-country average, the predicted persistence and volatility of the current account is 0.94 and 2.39, respectively. Unlike that in the pure SI model, the predicted persistence of 
changes in consumption is now suppressed to 0.34 , which is fairly close to the data of 0.25 .

It may not be surprising that imperfect capital mobility leads to the good performance of the SI model because the hybrid SI model has one additional free parameter $\lambda$. However, imperfect capital mobility alone does not necessarily improve the predictions, unless information rigidity is incorporated. When we estimate $\lambda$ in the hybrid $\mathrm{RE}$ model with the same objective function, the estimated $\lambda$ turns out to be zero in 11 out of 16 countries. ${ }^{26}$ In our exercise, the improvement of predictions are achieved only under the information rigidity.

\subsection{Degrees of information rigidity and imperfect capital mobility}

While the hybrid SI model achieves a fairly good model performance, we should note a caveat in the estimated values of $\omega$ and $\lambda$. The hybrid SI model can achieve good performance under relatively high degrees of information rigidity and imperfect capital mobility. Table 5 shows $\omega$ and $\lambda$ that are estimated for each country in the two SI models. On average, $\hat{\omega}$ is 0.64 in the pure SI model and 0.89 in the hybrid SI model. These values imply that the average duration of holding information until the next update is 2.8 years in the pure SI model and is 9.1 years in the hybrid SI model. ${ }^{27}$ The latter value seems extremely large compared to the average duration estimate of 1.3 years obtained by Mankiw and Reis (2007).

We also note that an improvement with the hybrid SI model relies on a high degree of imperfect capital mobility in some countries. While $\hat{\lambda}$ is only 0.08 in the Netherlands, it is almost one in Belgium and Germany under the parameter restriction of $\lambda \in[0,1)$. Overall, however, the cross-country average of $\hat{\lambda}$ is 0.58 . This average is not extremely high in the consumption literature though it may be considered to be high compared to the estimates of some previous studies. ${ }^{28}$ For single country's estimates, they are statistically significant in many countries. In the right panel of Table 5 , we report $Q(\tilde{\theta})-Q(\hat{\theta})$, the difference between the objective functions evaluated at $\tilde{\theta}$ and $\hat{\theta}$. The difference is asymptotically distributed as $\chi^{2}(1)$ under the null hypothesis of $\lambda=0$. In 11 out of 16 countries, $\lambda$ is found to be statistically significant at the conventional significance level.

An interpretation of the high degrees of information rigidity and imperfect capital mobility may be that the ICA model does not allow for other possible frictions and that the

\footnotetext{
${ }^{26}$ The countries in which the estimated $\lambda$ is zero are Australia, Austria, Belgium, Canada, Denmark, Finland, Iceland, Italy, Japan, Norway, and Sweden. We also find that the estimated $\lambda$ turns out to be unity in four countries of France, Germany, the Netherlands, and the UK.

${ }^{27}$ Given the annual data, the average duration of holding information until the next update can be computed from $(1-0.64)^{-1}=2.8$ and $(1-0.89)^{-1}=9.1$.

${ }^{28}$ For example, Campbell and Mankiw (1990) use the US data and estimate $\lambda$ to range between 0.30 and 0.64 . Reis (2006) estimates $\lambda$, considering SI explicitly. His estimate of $\lambda$ is quite low, a value between 0.05 and 0.15 .
} 
estimated parameters may reflect such frictions outside the model. Therefore, while the SI model continues to be a promising approach to explaining the current account, introducing other types of frictions and/or shocks into SI model may result in more reasonable estimates for the degrees of information rigidity and imperfect capital mobility.

\section{Conclusions}

This paper extends the intertemporal current account (ICA) model with sticky information (SI). In our ICA model, consumers are inattentive to shock to net output and infrequently update their information, as developed by Mankiw and Reis (2002, 2007) and Reis (2006). Under the assumption that a permanent shock to net output drives the current account, the rational expectations model fails to predict a persistent and volatile current account as well as persistent changes in consumption. In our SI models, information rigidity improves the predicted persistence and volatility of the current account. If the SI model is extended with imperfect capital mobility as in Shibata and Shintani (1998), our SI model exhibits a fairly good performance in predicting changes in consumption as well as the current account. In particular, the SI model almost perfectly explains the data of the 16 OECD countries if the degrees of information rigidities and imperfect capital mobility are sufficiently high.

Our analysis also suggests that these frictions may need to be introduced into a richer model of the current account to reduce too much reliance on imperfect information and imperfect capital mobility. Toward this end, it may be important to consider the production economy and to include other frictions in the ICA model. ${ }^{29}$ Consideration of other shocks, such as the world interest rate shock and the exchange rate shock, may also be helpful. ${ }^{30}$ Extending the ICA model in these directions under information rigidity would be an important step for future research.

\section{References}

[1] Bergin, P. R. and S. M. Sheffrin (2000). "Interest rates, exchange rates and present value models of the current account," Economic Journal, 110 (463), pp. 535-558.

[2] Bilbiie, F. O. (2008). "Limited asset markets participation, monetary policy and (inverted) aggregate demand logic," Journal of Economic Theory, 140 (1), pp. 162-196.

\footnotetext{
${ }^{29}$ One of the most important avenues of research may be the general equilibrium model with SI by Ekinci (2017), although he focuses on a two-country model rather than on small open economies.

${ }^{30}$ For example, see Bergin and Sheffrin (2000) and Kano (2009).
} 
[3] Campbell, J. Y. and A. Deaton (1989). "Why is consumption so smooth?" Review of Economic Studies, 56 (3), pp. 357-373.

[4] Campbell, J. Y. and N. G. Mankiw (1989). "Consumption, income and interest rates: Reinterpreting the time series evidence," NBER Macroeconomics Annual 1989, Vol. 4, pp. 185-246: MIT Press.

[5] Campbell, J. Y. and N. G. Mankiw (1990). "Permanent income, current income, and consumption," Journal of Business 6 Economic Statistics, 8 (3), pp. 265-279.

[6] Campbell, J. Y. and N. G. Mankiw (1991). "The response of consumption to income: A cross-country investigation," European Economic Review, 35 (4), pp. 723-756.

[7] Carroll, C. D. and J. Slacalek (2007). "Sticky expectations and consumption dynamics," Unpublished manuscript.

[8] Carroll, C. D., J. Slacalek and M. Sommer (2011). "International evidence on sticky consumption growth," Review of Economics and Statistics, 93 (4), pp. 1135-1145.

[9] Coibion, O., Y. Gorodnichenko and S. Kumar (2018). "How do firms form their expectations? New survey evidence," American Economic Review, forthcoming.

[10] Crucini, M. J., M. Shintani and T. Tsuruga (2010). "Accounting for persistence and volatility of good-level real exchange rates: The role of sticky information," Journal of International Economics, 81 (1), pp. 48-60.

[11] Dovern, J., U. Fritsche and J. Slacalek (2012). "Disagreement among forecasters in G7 countries," Review of Economics and Statistics, 94 (4), pp. 1081-1096.

[12] Dynan, K. E. (2000). "Habit formation in consumer preferences: Evidence from panel data," American Economic Review, 90 (3), pp. 391-406.

[13] Ekinci, M. F. (2017). "Inattentive consumers and international business cycles," Journal of International Money and Finance, 72, pp. 1-27.

[14] Gabaix, X. (2016). "Behavioral macroeconomics via sparse dynamic programming," unpublished manuscript, New York University. 
[15] Galí J., J. D. López-Salido and J. Vallés (2004). "Rule-of-thumb consumers and the design of interest rate rules," Journal of Money, Credit, and Banking, 36 (4), pp. 739763.

[16] Galí J., J. D. López-Salido and J. Vallés (2007). "Understanding the effects of government spending on consumption," Journal of the European Economic Association, 5 (1), pp. $227-270$.

[17] Ghosh, A. R. (1995). "International capital mobility amongst the major industrialised countries: Too little or too much?" Economic Journal, 105 (428), pp. 107-128.

[18] Ghosh, A. R. and J. D. Ostry (1997). "Macroeconomic uncertainty, precautionary saving, and the current account," Journal of Monetary Economics, 40 (1), pp. 121-139.

[19] Glick, R. and K. Rogoff (1995). "Global versus country-specific productivity shocks and the current account," Journal of Monetary Economics, 35 (1), pp. 159-192.

[20] Gruber, J. W. (2004). "A present value test of habits and the current account," Journal of Monetary Economics, 51 (7), pp. 1495-1507.

[21] Guariglia, A. and M. Rossi (2002). "Consumption, habit formation, and precautionary saving: evidence from the British Household Panel Survey," Oxford Economic Papers, 54 (1), pp. 1-19.

[22] Işcan, T. B. (2002). "Present value tests of the current account with durables consumption," Journal of International Money and Finance, 21 (3), pp. 385-412.

[23] Kano, T. (2008). "A structural VAR approach to the intertemporal model of the current account," Journal of International Money and Finance, 27 (5), pp. 757-779.

[24] Kano, T. (2009). "Habit formation and the present-value model of the current account: Yet another suspect," Journal of International Economics, 78 (1), pp. 72-85.

[25] Kunieda, T. and A. Shibata (2005). "Credit constraints and the current account: A test for the Japanese economy," Journal of International Money and Finance, 24 (8), pp. 1261-1277. 
[26] Li, W., Y. Luo and J. Nie (2017). "Elastic attention, risk sharing, and international comovements," Journal of Economic Dynamics and Control, vol. 79, pp. 1-20.

[27] Luo, Y. (2008). "Consumption dynamics under information processing constraints," Review of Economic Dynamics, 11 (2), pp. 366-385.

[28] Luo, Y., J. Nie and E. R. Young (2012). "Robustness, information-processing constraints, and the current account in small open economies," Journal of International Economics, 88 (1), pp. 104-120.

[29] Luo, Y., J. Nie and E. R. Young (2015). "Slow information diffusion and the inertial behavior of durable consumption," Journal of the European Economic Association, 13 (5), pp. 805-840.

[30] Mankiw, N. G. and R. Reis (2002). "Sticky information versus sticky prices: A proposal to replace the New Keynesian Phillips curve," Quarterly Journal of Economics, 117 (4), pp. 1295-1328.

[31] Mankiw, N. G. and R. Reis (2007). "Sticky information in general equilibrium," Journal of the European Economic Association, 5 (2-3), pp. 603-613.

[32] Mankiw, N. G., R. Reis and J. Wolfers (2003). "Disagreement about inflation expectations," NBER Macroeconomics Annual, 18, pp. 209-248.

[33] Nason, J. M. and J. H. Rogers (2006). "The present-value model of the current account has been rejected: Round up the usual suspects," Journal of International Economics, 68 (1), pp. 159-187.

[34] Otto, G. (1992). "Testing a present-value model of the current account: Evidence from US and Canadian time series," Journal of International Money and Finance, 11 (5), pp. 414-430.

[35] Pischke, J.-S. (1995). "Individual income, incomplete information, and aggregate consumption," Econometrica, 63 (4), pp. 805-840.

[36] Reis, R. (2006). "Inattentive consumers," Journal of Monetary Economics, 53 (8), pp. 1761-1800. 
[37] Sheffrin, S. M. and W. T. Woo (1990). "Present value tests of an intertemporal model of the current account," Journal of International Economics, 29 (3), pp. 237-253.

[38] Shibata, A. and M. Shintani (1998). "Capital mobility in the world economy: An alternative test," Journal of International Money and Finance, 17 (5), pp. 741-756.

[39] Sims, C. A. (2003). "Implications of rational inattention," Journal of Monetary Economics, 50 (3), pp. 665-690.

[40] Sims, C. A. (2010). "Rational inattention and monetary economics," Handbook of Monetary Economics, in B. M. Friedman and M. Woodford (eds.), vol. 3, pp. 155-181.

[41] Uribe, M. and S. Schmitt-Grohé (2017) Open Economy Macroeconomics, Princeton University Press. 


\section{A Appendix}

\section{A.1 The maximization problem and the optimality conditions}

Our formal description of the consumer's maximization problem follows Mankiw and Reis (2007). Suppose that a consumer has the information set available in period $t$. We consider an inattentive consumer who receives the newest information only with the probability $1-\omega$ every period. Given the infrequent information updating and the information set in period $t$, he chooses a consumption plan to solve the following maximization problem:

$$
\begin{gathered}
\qquad\left(A_{t}, X_{t}\right)=\max _{\left\{C_{t+j, j}\right\}_{i=0}^{\infty}} \sum_{j=0}^{\infty}(\beta \omega)^{j} u\left(C_{t+j, j}\right) \\
+\beta(1-\omega) \mathbb{E}_{t} \sum_{j=0}^{\infty}(\beta \omega)^{j} V\left(A_{t+j+1}, X_{t+j+1}\right), \\
\text { subject to } A_{t+j+1}=(1+r) A_{t+j}+X_{t+j}-C_{t+j, j}, \quad \text { for } j=0,1,2, \ldots,
\end{gathered}
$$

where $V\left(A_{t}, X_{t}\right)$ is the value function of the consumer in period $t$. Using the information available in period $t$, he chooses the consumption plan $\left\{C_{t+j, j}\right\}_{j=0}^{\infty}$, where $C_{t+j, j}$ represents the amount of goods consumed in period $t+j$ but predetermined $j$ periods in advance. The value function is somewhat complicated since the plan is specified as consumption from period $t$ and revised once he receives the new information. Other variables, parameters, and the function $u(C)$ are defined in the main text.

The first-order condition and the envelope condition are

$$
\begin{aligned}
u^{\prime}\left(C_{t+j, j}\right) & =\beta(1-\omega) \mathbb{E}_{t} \sum_{k=0}^{\infty}[\beta \omega(1+r)]^{k} V^{\prime}\left(A_{t+j+k+1}, X_{t+j+k+1}\right), \\
V^{\prime}\left(A_{t}, X_{t}\right) & =\beta(1-\omega)(1+r) \mathbb{E}_{t} \sum_{k=0}^{\infty}[\beta \omega(1+r)]^{k} V^{\prime}\left(A_{t+k+1}, X_{t+k+1}\right),
\end{aligned}
$$

for $j=0,1,2, \ldots$, respectively. Here, $u^{\prime}(C)=d u(C) / d C$ and $V^{\prime}\left(A_{t}, X_{t}\right)$ is the partial derivative with respect to the foreign asset. That is, $V^{\prime}(A, X)=\partial V(A, X) / \partial A$.

Evaluating $(26)$ at $j=0$ yields $u^{\prime}\left(C_{t, 0}\right)=\beta(1-\omega) \mathbb{E}_{t} \sum_{k=0}^{\infty}[\beta \omega(1+r)]^{k} V^{\prime}\left(A_{t+k+1}, X_{t+k+1}\right)$. This result implies

$$
V^{\prime}\left(A_{t}, X_{t}\right)=(1+r) u^{\prime}\left(C_{t, 0}\right)
$$


Rewriting (27) recursively, we have

$$
\begin{aligned}
V^{\prime}\left(A_{t}, X_{t}\right)= & \beta(1-\omega)(1+r) \mathbb{E}_{t} \sum_{k=0}^{\infty}[\beta \omega(1+r)]^{k} V^{\prime}\left(A_{t+k+1}, X_{t+k+1}\right) \\
= & \beta(1-\omega)(1+r) \mathbb{E}_{t} V^{\prime}\left(A_{t+1}, X_{t+1}\right) \\
& +\beta \omega(1+r) \mathbb{E}_{t}\left\{\beta(1-\omega)(1+r) \sum_{k=0}^{\infty}[\beta \omega(1+r)]^{k} \mathbb{E}_{t+1} V\left(A_{t+k+2}, X_{t+k+2}\right)\right\} \\
= & \beta(1-\omega)(1+r) \mathbb{E}_{t} V^{\prime}\left(A_{t+1}, X_{t+1}\right)+\beta \omega(1+r) \mathbb{E}_{t} V^{\prime}\left(A_{t+1}, X_{t+1}\right) \\
= & \beta(1+r) \mathbb{E}_{t} V^{\prime}\left(A_{t+1}, X_{t+1}\right) .
\end{aligned}
$$

Combining (28) and (29), we have the Euler equation that is standard in the RE model:

$$
u^{\prime}\left(C_{t, 0}\right)=\beta(1+r) \mathbb{E}_{t} u^{\prime}\left(C_{t+1,0}\right)
$$

We next consider the expected marginal utility $\mathbb{E}_{t} u^{\prime}\left(C_{t+1,0}\right)$. Update $(26)$ by one period and set $j=0$. Then, we have $u^{\prime}\left(C_{t+1,0}\right)=\beta(1-\omega) \mathbb{E}_{t+1} \sum_{k=0}^{\infty}[\beta \omega(1+r)]^{k} V^{\prime}\left(A_{t+k+2}, X_{t+k+2}\right)$. By the law of iterated expectations,

$$
\begin{aligned}
\mathbb{E}_{t} u^{\prime}\left(C_{t+1,0}\right) & =\beta(1-\omega) \mathbb{E}_{t} \sum_{k=0}^{\infty}[\beta \omega(1+r)]^{k} V^{\prime}\left(A_{t+k+2}, X_{t+k+2}\right) \\
& =u^{\prime}\left(C_{t+1,1}\right) .
\end{aligned}
$$

Therefore, along with the assumption of $\beta(1+r)=1$, (30) implies

$$
C_{t+j, j}=C_{t, 0} \text { for } j=1,2, \ldots
$$

We note that the optimal consumption in period $t$ under the SI and RE models must be the same because the information used to determine the optimal period- $t$ consumption is identical. Therefore, (2) and (31) imply (6) in the main text: $C_{t+j, j}=r A_{t}+X_{t}^{p}$, for $j=0,1,2, \ldots$

\section{A.2 Inattentive consumer's saving}

Using (6), it is straightforward to derive (9) in the main text:

$$
\begin{aligned}
S_{t+j, j} & =A_{t+j+1}-A_{t+j}=r A_{t+j}+X_{t+j}-C_{t+j, j} \\
& =r\left(A_{t+j}-A_{t}\right)+X_{t+j}-X_{t}^{p} \\
& =r \underbrace{\left(A_{t+j}-A_{t+j-1}\right)}_{s_{t+j-1, j-1}}+X_{t+j}-X_{t+j-1}+\underbrace{r\left(A_{t+j-1}-A_{t}\right)+X_{t+j-1}-X_{t}^{p}}_{s_{t+j-1, j-1}} \\
& =(1+r) S_{t+j-1, j-1}+\Delta X_{t+j} \text { for } j=1,2,3, \ldots .
\end{aligned}
$$




\section{A.3 Proof of Proposition 1}

\section{A.3.1 Derivation of (13)}

To obtain the current account in the economy, we aggregate all individual savings over information differing across households. Notice that $S_{t, k}$ is the period- $t$ saving of the inattentive consumers who updated their information $k$ periods ago. Using (32), we have an individual's saving in period $t$ :

$$
\begin{aligned}
S_{t, k} & =(1+r) S_{t-1, k-1}+\Delta X_{t}=(1+r)\left[(1+r) S_{t-2, k-2}+\Delta X_{t-1}\right]+\Delta X_{t} \\
& =(1+r)^{2} S_{t-2, k-2}+\Delta X_{t}+(1+r) \Delta X_{t-1} \\
& =\ldots \\
& =(1+r)^{k} S_{t-k, 0}+\Delta X_{t}+(1+r) \Delta X_{t-1}+\ldots+(1+r)^{k-1} \Delta X_{t-k+1},
\end{aligned}
$$

where $S_{t-k .0}=X_{t-k}-X_{t-k}^{p}$ for $k=1,2,3, \ldots$. The distribution of $S_{t, k}$ follows (10) in the main text so that the current account is aggregated by

$$
\begin{aligned}
C A_{t}= & (1-\omega) S_{t, 0} \\
& +(1-\omega) \omega(1+r) S_{t-1,0}+(1-\omega) \omega \Delta X_{t} \\
& +(1-\omega) \omega^{2}(1+r)^{2} S_{t-2,0}+(1-\omega) \omega^{2} \Delta X_{t}+(1-\omega) \omega^{2}(1+r) \Delta X_{t-1} \\
& +\ldots
\end{aligned}
$$

Using the definition of $\omega^{*}=\omega(1+r)$, this equation can be rearranged as

$$
\begin{aligned}
C A_{t}= & (1-\omega) \sum_{k=0}^{\infty}\left(\omega^{*}\right)^{k} S_{t-k, 0} \\
& +\omega(1-\omega) \sum_{k=0}^{\infty} \omega^{k} \Delta X_{t}+\omega \omega^{*}(1-\omega) \sum_{k=0}^{\infty} \omega^{k} \Delta X_{t-1}+\omega\left(\omega^{*}\right)^{2}(1-\omega) \sum_{k=0}^{\infty} \omega^{k} \Delta X_{t-2}+\ldots \\
= & (1-\omega) \sum_{k=0}^{\infty}\left(\omega^{*}\right)^{k} S_{t-k, 0}+\omega\left[\Delta X_{t}+\omega^{*} \Delta X_{t-1}+\left(\omega^{*}\right)^{2} \Delta X_{t-2}+\ldots\right] \\
= & \sum_{k=0}^{\infty}\left(\omega^{*}\right)^{k}\left[(1-\omega) S_{t-k, 0}+\omega \Delta X_{t-k}\right] .
\end{aligned}
$$

Assume that $\omega^{*}=\omega(1+r)<1$. Then, using the lag operator $L, C A_{t}=\left(1-\omega^{*} L\right)^{-1}\left[(1-\omega) S_{t, 0}+\omega \Delta X_{t}\right]$. This equation is equivalent to (13) in Proposition 1.

\section{A.3.2 Derivation of (14)}

In the proof, we derive the stochastic process of $c a_{t}$ under the generalized case of non-zero $\mu$. It is convenient because the general case allows us to derive (22) and (23) in Proposition 3. To prove 
the second part of Proposition 1, we divide both sides of (13) by $X_{t-1}$ :

$$
\exp \left(g_{t}\right) c a_{t}=\omega^{*} c a_{t-1}+(1-\omega) \exp \left(g_{t}\right) s_{t, 0}+\omega\left[\exp \left(g_{t}\right)-1\right]
$$

where $s_{t, 0} \equiv S_{t, 0} / X_{t}$. We note that the steady state value of $s_{t, 0}$ equals the steady state value of $c a_{t}$ because $S_{t, 0}$ is identical to the current account under the RE model. Let $c a$ be the steady state value of $c a_{t}$. In the steady state, (33) becomes

$$
\exp (\mu) \cdot c a=\omega^{*} c a+(1-\omega) \exp (\mu) c a+\omega[\exp (\mu)-1]
$$

Noting that $\exp (\mu)=1+\mu, \omega^{*}=\omega(1+r)$, we can solve the above equation for $c a$ as follows:

$$
c a=-\frac{\mu}{r-\mu} .
$$

That is, $c a$ is zero if and only if $\mu=0$. In addressing the case of non-zero $\mu$, it is convenient to introduce the deviations of a variable from the mean:

$$
c \hat{a}_{t}=c a_{t}-c a, \hat{s}_{t, 0}=s_{t, 0}-c a, \text { and } \hat{g}_{t}=g_{t}-\mu .
$$

The first-order Taylor expansion of both sides of (33) around the steady state is

$\exp (\mu) \cdot c \hat{a}_{t}+[\exp (\mu) c a] \hat{g}_{t}=\omega^{*} c \hat{a}_{t-1}+(1-\omega) \exp (\mu) \hat{s}_{t, 0}+(1-\omega)[\exp (\mu) c a] \hat{g}_{t}+\omega \exp (\mu) \hat{g}_{t}$ Arranging terms yields

$$
c \hat{a}_{t}=\omega_{\mu}^{*} c \hat{a}_{t-1}+(1-\omega) \hat{s}_{t, 0}+\omega(1-c a) \hat{g}_{t}
$$

where $\omega_{\mu}^{*}=\omega(1+r) / \exp (\mu)=\omega(1+r) /(1+\mu)$.

We would like to rewrite the last two terms of (35). As a preparation, note that $s_{t, 0}=1-X_{t}^{p} / X_{t}$ since $S_{t, 0}=X_{t}-X_{t}^{p}$. Here, we have

$$
\frac{X_{t}^{p}}{X_{t}}=\frac{r}{1+r} \sum_{j=0}^{\infty}\left(\frac{1}{1+r}\right)^{j} \mathbb{E}_{t}\left(\frac{X_{t+j}}{X_{t}}\right)
$$

Focusing on each $X_{t+j} / X_{t}$ inside the summation, we have the first-order Taylor expansions of $X_{t+j} / X_{t}$ : 


$$
\begin{aligned}
& \frac{X_{t}}{X_{t}}=(1+\mu)^{0} \times 1 \\
& \frac{X_{t+1}}{X_{t}} \simeq(1+\mu)^{1} \times\left(1+\hat{g}_{t+1}\right)(1+\mu)^{2} \times\left(1+\hat{g}_{t+1}+\hat{g}_{t+2}\right) \\
& \frac{X_{t+2}}{X_{t}} \simeq \ldots \\
& \frac{X_{t+j}}{X_{t}} \simeq(1+\mu)^{j} \times\left(1+\hat{g}_{t+1}+\hat{g}_{t+2}+\ldots+\hat{g}_{t+j}\right) .
\end{aligned}
$$

Substituting these approximants into $X_{t}^{p} / X_{t}$ in (36), we have

$$
\begin{aligned}
\frac{X_{t}^{p}}{X_{t}} & \simeq \frac{r}{1+r} \sum_{j=0}^{\infty}\left(\frac{1+\mu}{1+r}\right)^{j}+\frac{r}{1+r} \sum_{j=1}^{\infty}\left(\frac{1+\mu}{1+r}\right)^{j} \mathbb{E}_{t} \hat{g}_{t+1}+\frac{r}{1+r} \sum_{j=2}^{\infty}\left(\frac{1+\mu}{1+r}\right)^{j} \mathbb{E}_{t} \hat{g}_{t+2}+\ldots \\
& =\frac{r}{r-\mu}+\frac{r}{r-\mu}\left(\frac{1+\mu}{1+r}\right) \mathbb{E}_{t} \hat{g}_{t+1}+\frac{r}{r-\mu}\left(\frac{1+\mu}{1+r}\right)^{2} \mathbb{E}_{t} \hat{g}_{t+2}+\ldots \\
& =\frac{r}{r-\mu}+\frac{r}{r-\mu} \sum_{j=1}^{\infty}\left(\frac{1+\mu}{1+r}\right)^{j} \mathbb{E}_{t} \hat{g}_{t+j} \\
& =\frac{r}{r-\mu}+\frac{r}{r-\mu} \frac{\phi}{(1+r) /(1+\mu)-\phi} \hat{g}_{t}
\end{aligned}
$$

where the last line is due to $\operatorname{AR}(1)$ process of $\hat{g}_{t}$.

Equation (37) provides the expression of the second term of (35). Since $\hat{s}_{t, 0}=1-X_{t}^{p} / X_{t}-c a$, the second term of (35) is given by

$$
(1-\omega) \hat{s}_{t, 0}=-(1-\omega) \frac{r}{r-\mu} \frac{\phi}{(1+r) /(1+\mu)-\phi} \hat{g}_{t}
$$

Plugging in (34) and (38) into (35) yields

$$
\begin{aligned}
c \hat{a}_{t} & =\omega_{\mu}^{*} c \hat{a}_{t-1}-(1-\omega) \frac{r}{r-\mu} \frac{\phi}{(1+r) /(1+\mu)-\phi} \hat{g}_{t}+\omega \frac{r}{r-\mu} \hat{g}_{t} \\
& =\omega_{\mu}^{*} c \hat{a}_{t-1}+\frac{r}{r-\mu}\left[\omega-(1-\omega) \frac{\phi}{(1+r) /(1+\mu)-\phi}\right] \hat{g}_{t} \\
& =\omega_{\mu}^{*} c \hat{a}_{t-1}+\frac{r}{r-\mu} \frac{\omega_{\mu}^{*}-\phi}{(1+r) /(1+\mu)-\phi} \hat{g}_{t} .
\end{aligned}
$$

Using $\hat{g}_{t}=\phi \hat{g}_{t-1}+\varepsilon_{t}=(1-\phi L)^{-1} \varepsilon_{t}$, we can further rewrite the above equation as

$$
c \hat{a}_{t}=\left(\omega_{\mu}^{*}+\phi\right) c \hat{a}_{t-1}-\left(\omega_{\mu}^{*} \phi\right) c \hat{a}_{t-2}+\frac{r}{r-\mu} \frac{\omega_{\mu}^{*}-\phi}{(1+r) /(1+\mu)-\phi} \varepsilon_{t},
$$

which proves (22) in the main text. Imposing $\mu=0$ also yields (14) in the main text. 


\section{A.4 Proof of Proposition 2}

\section{A.4.1 Derivation of (17)}

To obtain changes in the aggregate consumption $\Delta C_{t+1}$, we aggregate all individual changes in consumption between periods $t$ and $t+1$. Notice that consumers do not change their individual consumption if they do not realize shocks between period $t$ and $t+1$ (i.e., $C_{t+1, k+1}-C_{t, k}=0$ for any $k \geq 0$ ). Therefore, for aggregation, it suffices to consider only consumers who receive the newest information in period $t+1$. When aggregating changes in their consumption, however, we need to take into account the history of information updating. For this reason, we first consider a sequence of changes in consumption $\left\{C_{t+j+1,0}-C_{t+j, j}\right\}_{j=0}^{\infty}$, given the foreign asset holdings $A_{t}$. This sequence consists of changes in consumption for an individual consumer, conditional on the fact that he receives no additional information between $t$ and $t+j+1$. We derive the expression for the changes in individual consumption as accumulated forecast errors. We then cross-sectionally aggregate changes in individual consumption differing across histories of individual information updating. The aggregation is made based on the distribution of information updating.

Consider a sequence of changes in consumption $\left\{C_{t+j+1,0}-C_{t+j, j}\right\}_{j=0}^{\infty}$. The simplest is the case of $j=0$ (i.e., $C_{t+1,0}-C_{t, 0}$ ). If a consumer with information in period $t$ updates the information in period $t+1$, the changes in consumption are the same as that in the RE model:

$$
\begin{aligned}
C_{t+1,0}-C_{t, 0} & =r\left(A_{t+1}-A_{t}\right)+\left(X_{t+1}^{p}-X_{t}^{p}\right) \\
& =r S_{t, 0}+\left(X_{t+1}^{p}-X_{t}^{p}\right) \\
& =r X_{t}+\left(X_{t+1}^{p}-(1+r) X_{t}^{p}\right) \\
& =\Delta \mathbb{E}_{t+1} X_{t+1}^{p},
\end{aligned}
$$

where the first equality uses the optimal consumption given by $C_{t, 0}=r A_{t}+X_{t}^{p}$ (See (6) in the main text); the second equality arises from $A_{t+1}-A_{t}=S_{t, 0}$; the third equality is from $S_{t, 0}=X_{t}-X_{t}^{p}$; and the final equality can be obtained from the definition of the non-financial permanent income $X_{t}^{p}=r /(1+r) \sum_{j=0}^{\infty}(1+r)^{-j} \mathbb{E}_{t} X_{t+j}$. Equation (40) indicates that changes in consumption in period $t+1$ equal unrecognized changes in permanent income.

Next, consider the case of $j=1$. Suppose that a consumer with information in period $t$ does not update his information set in period $t+1$, but updates the information in period $t+2$. Changes in consumption between periods $t+1$ and $t+2$ can analogously be calculated as

$$
\begin{aligned}
C_{t+2,0}-C_{t+1,1} & =C_{t+2,0}-C_{t, 0} \\
& =r\left(A_{t+2}-A_{t+1}+A_{t+1}-A_{t}\right)+\left(X_{t+2}^{p}-X_{t+1}^{p}\right)+\left(X_{t+1}^{p}-X_{t}^{p}\right) \\
& =r S_{t+1,1}+\left(X_{t+2}^{p}-X_{t+1}^{p}\right)+r S_{t, 0}+\left(X_{t+1}^{p}-X_{t}^{p}\right) \\
& =r S_{t+1,1}+\left(X_{t+2}^{p}-X_{t+1}^{p}\right)+\Delta \mathbb{E}_{t+1} X_{t+1}^{p} .
\end{aligned}
$$


Here, the third equality is based on the fact that $A_{t+2}-A_{t+1}=S_{t+1,1}$ because the consumer does not update information in period $t+1$. The last equality can be derived from (40). Furthermore, the first two terms of the right-hand side can be rewritten as

$$
\begin{aligned}
r S_{t+1,1}+\left(X_{t+2}^{p}-X_{t+1}^{p}\right) & =r\left[(1+r) S_{t, 0}+\Delta X_{t+1}\right]+\left(X_{t+2}^{p}-X_{t+1}^{p}\right) \\
& =r\left[r X_{t}+X_{t+1}^{p}-(1+r) X_{t}^{p}\right]+\left[r X_{t+1}+\left(X_{t+2}^{p}-(1+r) X_{t+1}^{p}\right)\right] \\
& =r \Delta \mathbb{E}_{t+1} X_{t+1}^{p}+\Delta \mathbb{E}_{t+2} X_{t+2}^{p}
\end{aligned}
$$

where the first equality is due to (32); the second equality is obtained from arranging terms with $S_{t, 0}=X_{t}-X_{t}^{p}$; and the third equality is due to (40). Substituting the above equation into (41), we obtain changes in consumption when the consumer with information in period $t$ updates information in period $t+2$ :

$$
C_{t+2,0}-C_{t+1,1}=\Delta \mathbb{E}_{t+2} X_{t+2}^{p}+(1+r) \Delta \mathbb{E}_{t+1} X_{t+1}^{p}
$$

This equation indicates that, if he updates the information in period $t+2$ but did not update it in period $t+1$, the changes in consumption include the unrecognized changes in permanent income in both periods $t+1$ and $t+2$.

For the general case of $j>1$, we repeat the above calculation. The general expression of changes in individual consumption is

$C_{t+j, 0}-C_{t+j-1, j-1}=\Delta \mathbb{E}_{t+j} X_{t+j}^{p}+(1+r) \Delta \mathbb{E}_{t+j-1} X_{t+j-1}^{p}+\ldots+(1+r)^{j-1} \Delta \mathbb{E}_{t+1} X_{t+1}^{p}, \quad$ for $j=1,2, \ldots$

We now aggregate the consumption change between $t$ and $t+1$ across all consumers, using the distribution of inattentive consumers: $C_{t}=(1-\omega) \sum_{k=0}^{\infty} \omega^{k} C_{t, k}$. Recall that it is sufficient to consider only consumers who receive the newest information in period $t+1$. The fraction of information-updating consumers is $1-\omega$. Therefore, changes in the aggregate consumption become

$$
\begin{aligned}
\Delta C_{t+1}=(1- & \omega)^{2}\left\{\Delta \mathbb{E}_{t+1} X_{t+1}^{p}\right. \\
+ & \omega\left[\Delta \mathbb{E}_{t+1} X_{t+1}^{p}+(1+r) \Delta \mathbb{E}_{t} X_{t}^{p}\right] \\
+ & \omega^{2}\left[\Delta \mathbb{E}_{t+1} X_{t+1}^{p}+(1+r) \Delta \mathbb{E}_{t} X_{t}^{p}+(1+r)^{2} \Delta \mathbb{E}_{t-1} X_{t-1}^{p}\right] \\
+ & \left.\omega^{3}\left[\Delta \mathbb{E}_{t+1} X_{t+1}^{p}+(1+r) \Delta \mathbb{E}_{t} X_{t}^{p}+(1+r)^{2} \Delta \mathbb{E}_{t-1} X_{t-1}^{p}+(1+r)^{3} \Delta \mathbb{E}_{t-2} X_{t-2}^{p}\right]+\ldots\right\}
\end{aligned}
$$

In the above equation, the first line in the curly brackets represents changes in consumption for consumers whose period- $t$ consumption was $C_{t, 0}$. The second line points to that for consumers whose period- $t$ consumption was $C_{t, 1}\left(=C_{t-1,0}\right)$. We can understand the remaining lines analogously. This 
equation can further be simplified to

$$
\begin{aligned}
\Delta C_{t+1}= & (1-\omega)\left[(1-\omega) \sum_{k=0}^{\infty} \omega^{k} \Delta \mathbb{E}_{t+1} X_{t+1}^{p}\right. \\
& +(1+r) \omega(1-\omega) \sum_{k=0}^{\infty} \omega^{k} \Delta \mathbb{E}_{t} X_{t}^{p} \\
& \left.+(1+r)^{2} \omega^{2}(1-\omega) \sum_{k=0}^{\infty} \omega^{k} \Delta \mathbb{E}_{t-1} X_{t-1}^{p}+\ldots\right] \\
= & (1-\omega)\left[\Delta \mathbb{E}_{t+1} X_{t+1}^{p}+\omega^{*} \Delta \mathbb{E}_{t} X_{t}^{p}+\left(\omega^{*}\right)^{2} \Delta \mathbb{E}_{t-1} X_{t-1}^{p}+\ldots\right] \\
= & \frac{1-\omega}{1-\omega^{*} L} \Delta \mathbb{E}_{t+1} X_{t+1}^{p}
\end{aligned}
$$

where the second equality comes from $(1-\omega) \sum_{k=0}^{\infty} \omega^{k}=1$. By multiplying $1-\omega^{*} L$ by both sides and arranging terms, we obtain (17) in the main text:

$$
\Delta C_{t+1}=\omega^{*} \Delta C_{t}+(1-\omega) \Delta \mathbb{E}_{t+1} X_{t+1}^{p}
$$

\section{A.4.2 Derivation of (18)}

Turning to the derivation of (18), divide both sides of (17) by $X_{t}$ :

$$
\Delta c_{t+1}=\omega^{*} \exp \left(-g_{t}\right) \Delta c_{t}+(1-\omega) \Delta \mathbb{E}_{t+1}\left(\frac{X_{t+1}^{p}}{X_{t}}\right) .
$$

We approximate each term in the right-hand side of (46). First, the first-order Taylor approximation of the first term is

$$
\omega^{*} \exp \left(-g_{t}\right) \Delta c_{t} \simeq \omega^{*} \exp (-\mu)(\Delta c)+\omega^{*} \exp (-\mu)\left(\Delta c_{t}-\Delta c\right)-\frac{\omega^{*}}{1+\mu}(\Delta c) \hat{g}_{t}
$$

where $\Delta c$ is the steady state value of changes in consumption (divided by net output). In the steady state, however, $\Delta c=0$. Therefore, noting that $\exp (-\mu)=(1+\mu)^{-1}$ and $\omega_{\mu}^{*} \equiv \omega(1+r) /(1+\mu)$, we can simplify the above equation as

$$
\omega^{*} \exp \left(-g_{t}\right) \Delta c_{t} \simeq \omega_{\mu}^{*} \Delta c_{t}
$$


The second term of the right-hand side of (46) includes $\mathbb{E}_{t+1}\left(X_{t+1}^{p} / X_{t}\right)$, which can be approximated by

$$
\begin{aligned}
\mathbb{E}_{t+1}\left(\frac{X_{t+1}^{p}}{X_{t}}\right) & =\frac{r}{1+r} \sum_{j=0}^{\infty}(1+r)^{-j} \mathbb{E}_{t+1}\left(\frac{X_{t+j+1}}{X_{t}}\right) \\
& =r \sum_{j=1}^{\infty}\left(\frac{1}{1+r}\right)^{j} \mathbb{E}_{t+1}\left(\frac{X_{t+j}}{X_{t}}\right) \\
& \simeq r \sum_{j=1}^{\infty}\left(\frac{1+\mu}{1+r}\right)^{j} \mathbb{E}_{t+1}\left(1+\hat{g}_{t+1}+\hat{g}_{t+2}+\ldots+\hat{g}_{t+j}\right) \\
& =r \sum_{j=1}^{\infty}\left(\frac{1+\mu}{1+r}\right)^{j}+r \sum_{j=1}^{\infty}\left(\frac{1+\mu}{1+r}\right)^{j} \mathbb{E}_{t+1} \hat{g}_{t+1}+\left(\frac{1+\mu}{1+r}\right) r \sum_{j=1}^{\infty}\left(\frac{1+\mu}{1+r}\right)^{j} \mathbb{E}_{t+1} \hat{g}_{t+2}+\ldots \\
& =\frac{r(1+\mu)}{r-\mu}+\frac{r(1+\mu)}{r-\mu} \sum_{j=0}^{\infty}\left(\frac{1+\mu}{1+r}\right)^{j} \mathbb{E}_{t+1} \hat{g}_{t+j+1} .
\end{aligned}
$$

Because $\hat{g}_{t+1}$ follows $\mathrm{AR}(1)$ process, we can simplify the equation as

$$
\begin{aligned}
\mathbb{E}_{t+1}\left(\frac{X_{t+1}^{p}}{X_{t}}\right) & \simeq \frac{r(1+\mu)}{r-\mu}+\frac{r(1+\mu)}{r-\mu} \sum_{j=0}^{\infty}\left(\frac{1+\mu}{1+r} \phi\right)^{j} \hat{g}_{t+1} \\
& =\frac{r(1+\mu)}{r-\mu}+\frac{r(1+\mu)}{r-\mu} \frac{1+r}{1+r-(1+\mu) \phi} \hat{g}_{t+1} .
\end{aligned}
$$

Using the law of iterated expectations, we obtain the first-order approximation of $\Delta \mathbb{E}_{t+1}\left(X_{t+1}^{p} / X_{t}\right)=$ $\mathbb{E}_{t+1}\left(X_{t+1}^{p} / X_{t}\right)-\mathbb{E}_{t}\left(X_{t+1}^{p} / X_{t}\right):$

$$
\mathbb{E}_{t}\left(\frac{X_{t+1}^{p}}{X_{t}}\right) \simeq \frac{r(1+\mu)}{r-\mu}+\frac{r(1+\mu)}{r-\mu} \frac{1+r}{1+r-(1+\mu) \phi} \phi \hat{g}_{t}
$$

Therefore,

$$
\begin{aligned}
\Delta \mathbb{E}_{t+1}\left(\frac{X_{t+1}^{p}}{X_{t}}\right) & =\frac{r(1+\mu)}{r-\mu} \frac{1+r}{1+r-(1+\mu) \phi}\left(\hat{g}_{t+1}-\phi \hat{g}_{t}\right) \\
& =\frac{r(1+\mu)}{r-\mu} \frac{1+r}{1+r-(1+\mu) \phi} \varepsilon_{t+1} .
\end{aligned}
$$

We now substitute (47) and (48) into (46):

$$
\Delta c_{t+1}=\omega_{\mu}^{*} \Delta c_{t}+(1-\omega) \frac{r}{r-\mu} \frac{(1+r)(1+\mu)}{1+r-(1+\mu) \phi} \varepsilon_{t+1}
$$

which proves (23) in the main text. Imposing $\mu=0$ also leads to (18) in the main text. 


\section{A.5 Proof of Corollary 6}

From the definition of the first-order autocorrelation, we calculate $\rho_{\Delta c}^{H Y}=\operatorname{Cov}\left(\Delta c_{t+1}^{H Y}, \Delta c_{t}^{H Y}\right) / \operatorname{Var}\left(\Delta c_{t}^{H Y}\right)$. Changes in consumption under the hybrid model are expressed as $\Delta C_{t+1}^{H Y}=(1-\lambda) \Delta C_{t+1}+$ $\lambda \Delta X_{t+1}$, which we normalize by $X_{t}$ to obtain $\Delta c_{t+1}^{H Y}=(1-\lambda) \Delta c_{t+1}+\lambda g_{t}$.

First, $\operatorname{Cov}\left(\Delta c_{t+1}^{H Y}, \Delta c_{t}^{H Y}\right)$, the numerator of $\rho_{\Delta c}^{H Y}$, is given by

$$
\begin{aligned}
\operatorname{Cov}\left(\Delta c_{t+1}^{H Y}, \Delta c_{t}^{H Y}\right)= & (1-\lambda)^{2} \operatorname{Cov}\left(\Delta c_{t+1}, \Delta c_{t}\right)+\lambda(1-\lambda) \operatorname{Cov}\left(g_{t+1}, \Delta c_{t}\right) \\
& +\lambda(1-\lambda) \operatorname{Cov}\left(\Delta c_{t+1}, g_{t}\right)+\lambda^{2} \operatorname{Cov}\left(g_{t+1}, g_{t}\right)
\end{aligned}
$$

Because both $\Delta c_{t}$ and $g_{t}$ follow the AR(1) process (see Proposition 2), $\operatorname{Cov}\left(\Delta c_{t+1}, \Delta c_{t}\right)=\omega^{*} \operatorname{Var}\left(\Delta c_{t}\right)$, $\operatorname{Cov}\left(g_{t+1}, \Delta c_{t}\right)=\omega^{*} \operatorname{Cov}\left(g_{t}, \Delta c_{t}\right), \operatorname{Cov}\left(\Delta c_{t+1}, g_{t},\right)=\phi \operatorname{Cov}\left(g_{t}, \Delta c_{t}\right)$, and $\operatorname{Cov}\left(g_{t+1}, g_{t}\right)=\phi \operatorname{Var}\left(g_{t}\right)$. Substituting these expressions into the above equation yields

$$
\begin{aligned}
\operatorname{Cov}\left(\Delta c_{t+1}^{H Y}, \Delta c_{t}^{H Y}\right)= & {\left[(1-\lambda)^{2} \operatorname{Var}\left(\Delta c_{t}\right)+\lambda(1-\lambda) \operatorname{Cov}\left(g_{t}, \Delta c_{t}\right)\right] \omega^{*} } \\
& +\left[\lambda^{2} \operatorname{Var}\left(g_{t}\right)+\lambda(1-\lambda) \operatorname{Cov}\left(g_{t}, \Delta c_{t}\right)\right] \phi .
\end{aligned}
$$

Next, the variance $\operatorname{Var}\left(\Delta c_{t}^{H Y}\right)$, the denominator of $\rho_{\Delta c}^{H Y}$, can similarly be calculated. The resulting expression is

$$
\begin{aligned}
\operatorname{Var}\left(\Delta c_{t}^{H Y}\right)= & (1-\lambda)^{2} \operatorname{Var}\left(\Delta c_{t}\right)+2 \lambda(1-\lambda) \operatorname{Cov}\left(g_{t}, \Delta c_{t}\right) \\
& +\lambda^{2} \operatorname{Var}\left(g_{t}\right) .
\end{aligned}
$$

Finally, taking the ratio of (50) to (51) yields

$$
\begin{aligned}
\rho_{\Delta c}^{H Y} & =\frac{(1-\lambda)^{2} \operatorname{Var}\left(\Delta c_{t}\right)+\lambda(1-\lambda) \operatorname{Cov}\left(g_{t}, \Delta c_{t}\right)}{\operatorname{Var}\left(\Delta c_{t}^{H Y}\right)} \omega^{*}+\frac{\lambda^{2} \operatorname{Var}\left(\hat{g}_{t}\right)+\lambda(1-\lambda) \operatorname{Cov}\left(g_{t}, \Delta c_{t}\right)}{\operatorname{Var}\left(\Delta c_{t}^{H Y}\right)} \phi \\
& =(1-\Lambda) \omega^{*}+\Lambda \phi
\end{aligned}
$$

which is (20) in the main text. We note that $\Lambda$ is a function not only of $\lambda$ but also of $\operatorname{Var}\left(\Delta c_{t}\right)$, $\operatorname{Cov}\left(g_{t}, \Delta c_{t}\right)$, and $\operatorname{Var}\left(g_{t}\right)$ :

$$
\begin{aligned}
\operatorname{Var}\left(\Delta c_{t}\right) & =\frac{1}{1-\left(\omega^{*}\right)^{2}}\left[\frac{(1-\omega)(1+r)}{1+r-\phi}\right]^{2} \sigma^{2}, \\
\operatorname{Cov}\left(g_{t}, \Delta c_{t}\right) & =\frac{1}{1-\omega^{*} \phi} \frac{(1-\omega)(1+r)}{1+r-\phi} \sigma^{2}, \\
\operatorname{Var}\left(g_{t}\right) & =\frac{1}{1-\phi^{2}} \sigma^{2}
\end{aligned}
$$

where all of these moments are a function of $\phi$, and $\omega$. In this proof, we used the assumption that $\mu=0$. In the case of $\mu \neq 0$, we can similarly calculate $\rho_{\Delta c}^{H Y}$, using the stochastic process of $\Delta c_{t+1}$ 
given by (23) in Proposition 3 and obtain the essentially same result.

\section{A.6 Proof of Proposition 3}

The derivations of (39) and (49) in the previous sections are applicable to the case of non-zero $\mu$. Therefore, we can derive (22) and (23) directly from (39) and (49), respectively. 

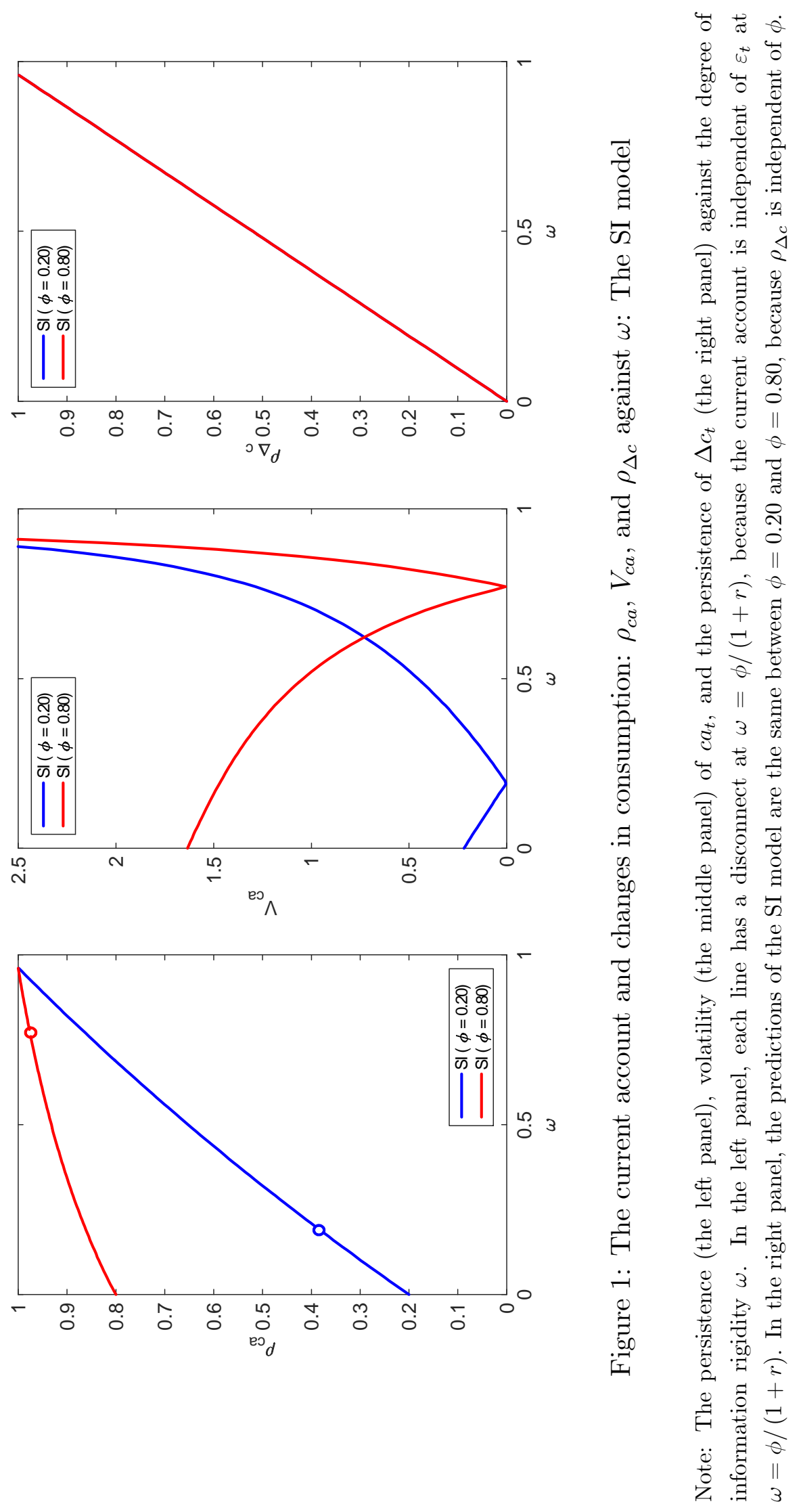

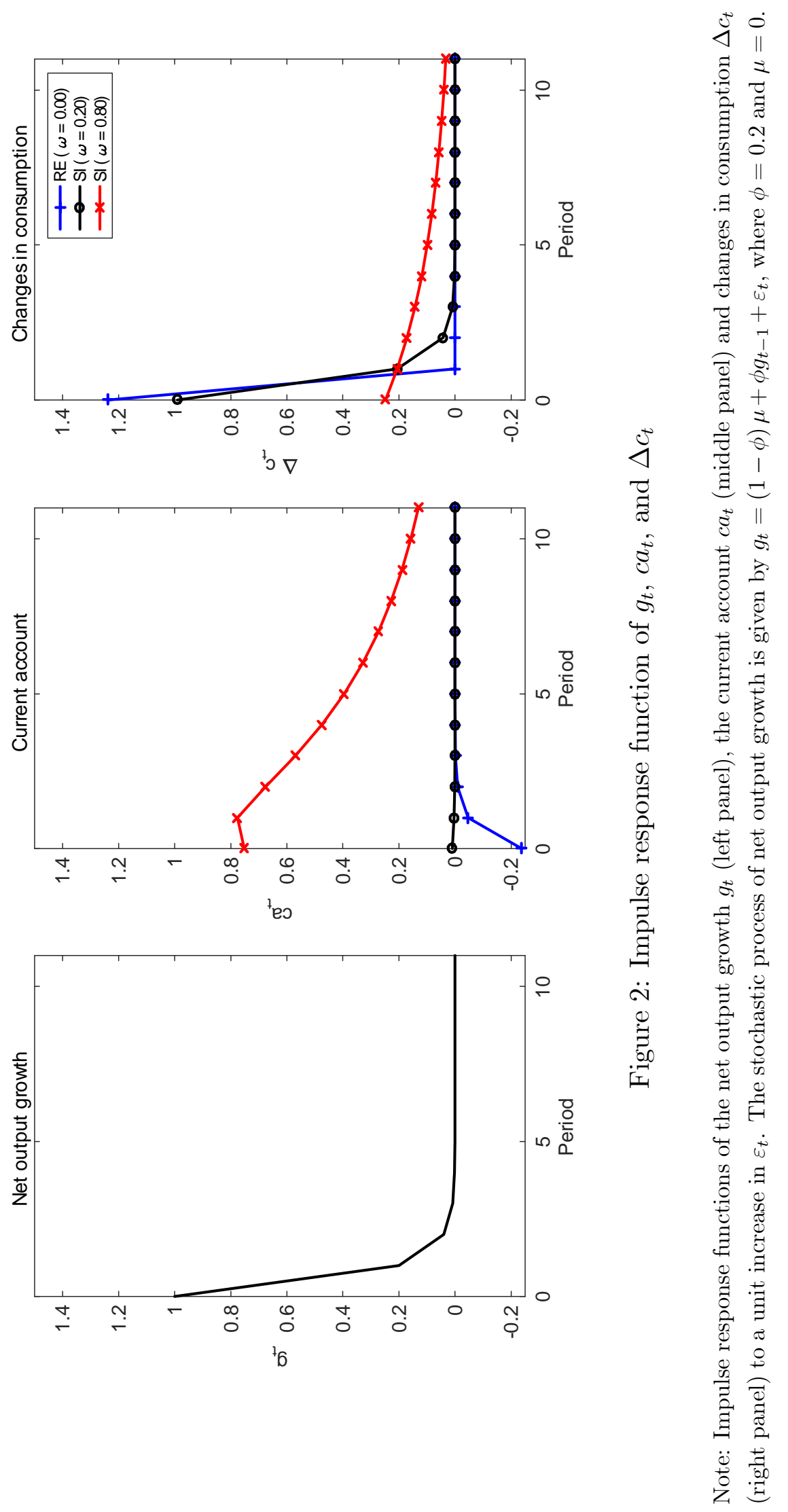

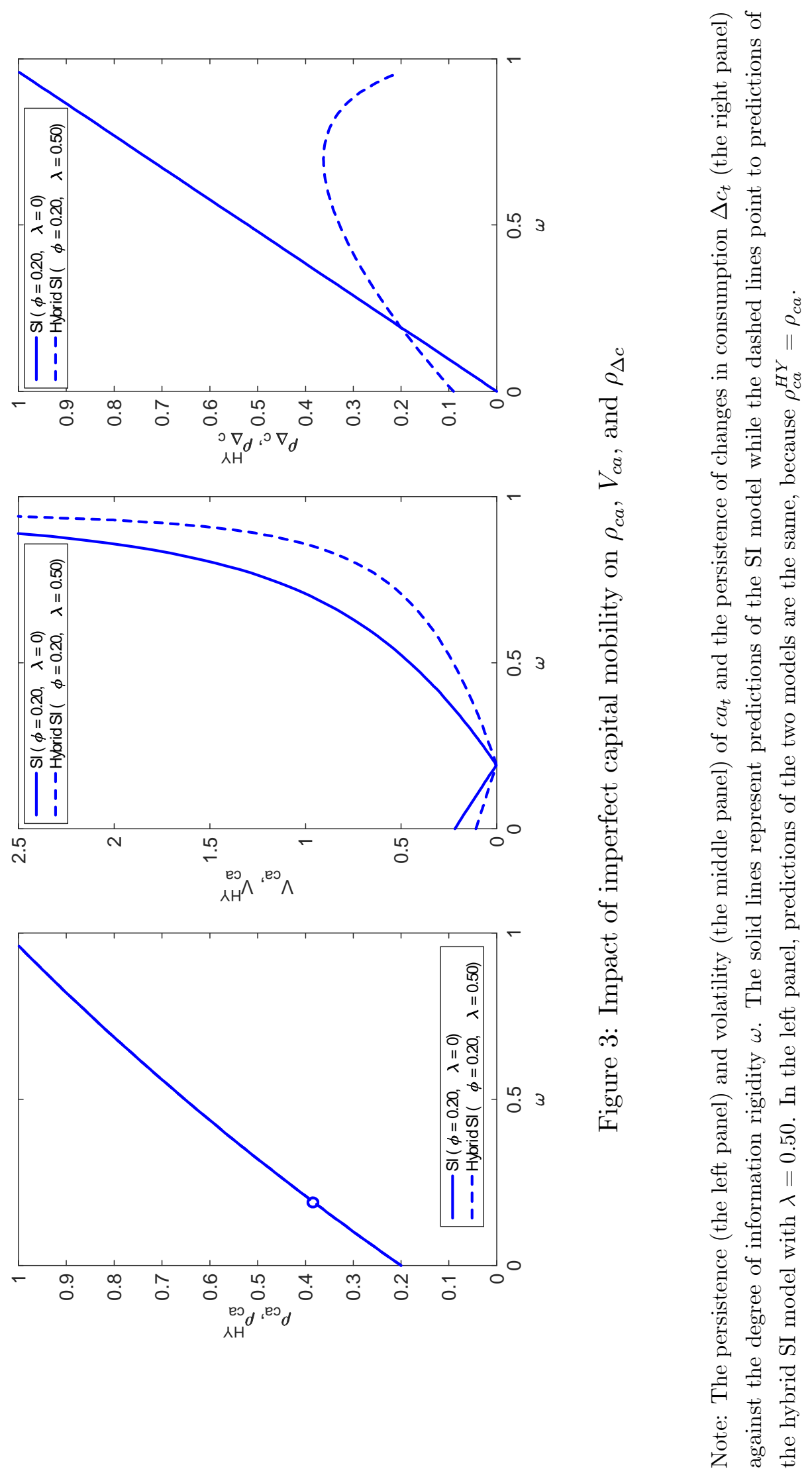
Table 1: Sample moments of the current account in rich OECD countries (1980-2013)

\begin{tabular}{cr}
\hline \hline & OECD data \\
\hline Persistence of current account $\left(\rho_{c a}^{\text {data }}\right)$ & 0.82 \\
Volatility of current account $\left(V_{c a}^{\text {data }}\right)$ & 2.29 \\
\hline Persistence of net output growth $\left(\phi^{\text {data }}\right)$ & 0.16 \\
\hline Persistence of changes in consumption $\left(\rho_{\Delta c}^{\text {data }}\right)$ & 0.25 \\
\hline \hline
\end{tabular}

Note: Numbers reported are the sample mean of actual moments across 16 OECD countries over 1980-2013. The selected countries include Australia, Austria, Belgium, Canada, Denmark, Finland, France, Germany, Iceland, Italy, Japan, the Netherlands, Norway, Sweden, UK, and US. In the table, the current account and changes in consumption are scaled as a percent of net output.

Table 2: Theoretical predictions of the RE models

\begin{tabular}{ccc}
\hline \hline & RE model & Hybrid RE model \\
\hline Persistence of current account & $\phi$ & $\phi$ \\
Volatility of current account & $\frac{\phi}{1+r-\phi}$ & $(1-\lambda) \frac{\phi}{1+r-\phi}$ \\
Persistence of changes in consumption & 0 & $\Lambda_{0} \phi$ \\
\hline \hline
\end{tabular}

Note: The theoretical predictions are made under the assumption that $g_{t}$ follows AR(1) process with $\mu=0$. In volatility of the current account, we assess $\phi=\phi^{\text {data }}=0.16$ and $r=0.04$. In persistence of changes in consumption, $\Lambda_{0}$ is a function of $r, \phi$, and $\lambda$, satisfying $0 \leq \Lambda_{0} \leq 1$ and takes a value between 0 and 1 . More specifically, $\Lambda_{0}=\Lambda_{N} / \Lambda_{D}$, where $\Lambda_{N}=\lambda(1-\lambda) \operatorname{Cov}\left(\Delta c_{t}, g_{t}\right)+\lambda^{2} \operatorname{Var}\left(g_{t}\right)$ and $\Lambda_{D}=(1-\lambda)^{2} \operatorname{Var}\left(\Delta c_{t}\right)+2 \lambda(1-$ $\lambda) \operatorname{Cov}\left(\Delta c_{t}, g_{t}\right)+\lambda^{2} \operatorname{Var}\left(g_{t}\right)$. The variances and covariance are given by $\operatorname{Var}\left(\Delta c_{t}\right)=[(1+r) /(1+r-\phi)]^{2} \sigma^{2}$, $\operatorname{Var}\left(g_{t}\right)=\left[1 /\left(1-\phi^{2}\right)\right] \sigma^{2}$, and $\operatorname{Cov}\left(\Delta c_{t}, g_{t}\right)=[(1+r) /(1+r-\phi)] \sigma^{2}$. 
Table 3: Predictions of the RE models $(\mu \neq 0)$

\begin{tabular}{|c|c|c|c|c|c|c|c|c|c|}
\hline & \multicolumn{3}{|c|}{ RE model } & \multicolumn{3}{|c|}{ Hybrid RE model } & \multicolumn{3}{|c|}{ OECD data } \\
\hline & $\rho_{c a}$ & $V_{c a}$ & $\rho_{\Delta c}$ & $\rho_{c a}^{H Y}$ & $V_{c a}^{H Y}$ & $\rho_{\Delta c}^{H Y}$ & $\rho_{c a}^{\text {data }}$ & $V_{c a}^{\text {data }}$ & $\rho_{\Delta c}^{\text {data }}$ \\
\hline Australia & 0.13 & 0.25 & 0.00 & 0.13 & 0.13 & 0.04 & 0.44 & 1.26 & 0.16 \\
\hline Austria & 0.03 & 0.07 & 0.00 & 0.03 & 0.03 & 0.01 & 0.88 & 1.89 & -0.02 \\
\hline Belgium & -0.01 & 0.01 & 0.00 & -0.01 & 0.01 & 0.00 & 0.78 & 2.50 & -0.29 \\
\hline Canada & 0.30 & 0.61 & 0.00 & 0.30 & 0.30 & 0.10 & 0.81 & 1.52 & 0.39 \\
\hline Denmark & -0.01 & 0.02 & 0.00 & -0.01 & 0.01 & -0.01 & 0.94 & 3.73 & 0.20 \\
\hline Finland & 0.17 & 0.37 & 0.00 & 0.17 & 0.18 & 0.05 & 0.92 & 2.77 & 0.34 \\
\hline France & 0.17 & 0.28 & 0.00 & 0.17 & 0.14 & 0.06 & 0.93 & 3.45 & 0.49 \\
\hline Germany & 0.15 & 0.36 & 0.00 & 0.15 & 0.18 & 0.04 & 0.95 & 2.20 & 0.11 \\
\hline Iceland & -0.16 & 0.23 & 0.00 & -0.16 & 0.12 & -0.06 & 0.71 & 2.32 & 0.25 \\
\hline Italy & 0.44 & 1.10 & 0.00 & 0.44 & 0.55 & 0.13 & 0.68 & 1.42 & 0.34 \\
\hline Japan & 0.17 & 0.37 & 0.00 & 0.17 & 0.19 & 0.05 & 0.75 & 0.89 & 0.01 \\
\hline The Netherlands & 0.20 & 0.42 & 0.00 & 0.20 & 0.21 & 0.06 & 0.85 & 2.07 & 0.74 \\
\hline Norway & 0.17 & 0.40 & 0.00 & 0.17 & 0.20 & 0.05 & 0.84 & 2.48 & 0.26 \\
\hline Sweden & 0.05 & 0.09 & 0.00 & 0.05 & 0.05 & 0.02 & 0.95 & 2.96 & 0.12 \\
\hline United Kingdom & 0.43 & 1.44 & 0.00 & 0.43 & 0.72 & 0.10 & 0.91 & 3.76 & 0.45 \\
\hline United States & 0.37 & 1.04 & 0.00 & 0.37 & 0.52 & 0.10 & 0.76 & 1.47 & 0.41 \\
\hline Mean & 0.16 & 0.44 & 0.00 & 0.16 & 0.22 & 0.05 & 0.82 & 2.29 & 0.25 \\
\hline
\end{tabular}

Note: The moments of the current account and changes in consumption predicted by the RE model (the left panel), the hybrid RE model (the middle panel) and the actual moments (the right panel). Each panel reports the persistence of the current account (in the first column), the volatility of the current account (in the second column), and the persistence of changes in consumption (in the third column), respectively. Here, the current account and changes in consumption are scaled by the net output and net output growth is assumed to follow $\mathrm{AR}(1)$ process with the mean growth rate $\mu^{\text {data }}$ and persistence of $\phi^{\text {data }}$. The mean growth rates of net output in the data $\left(\mu^{\text {data }}\right)$ are $1.76,1.86,1.47,1.23,1.26,1.80,1.27,2.10,1.66,1.28$, $1.81,1.66,1.94,1.66,2.00$, and 1.81 percent in the order of countries shown in the table. The value of $\phi$ used for the predictions can be confirmed from $\rho_{c a}$ in the first column of the left panel because the persistence of the current account is predicted to equal that of net output growth in the RE models. In the hybrid RE model shown in the middle panel, $\lambda$ is set to 0.5 . 
Table 4: Predictions of the SI models $(\mu \neq 0)$

\begin{tabular}{|c|c|c|c|c|c|c|c|c|c|}
\hline & \multicolumn{3}{|c|}{ SI model } & \multicolumn{3}{|c|}{ Hybrid SI model } & \multicolumn{3}{|c|}{ OECD data } \\
\hline & $\rho_{c a}$ & $V_{c a}$ & $\rho_{\Delta c}$ & $\rho_{c a}^{H Y}$ & $V_{c a}^{H Y}$ & $\rho_{\Delta c}^{H Y}$ & $\rho_{c a}^{\text {data }}$ & $V_{c a}^{\text {data }}$ & $\rho_{\Delta c}^{\text {data }}$ \\
\hline Australia & 0.59 & 0.91 & 0.50 & 0.59 & 0.91 & 0.50 & 0.44 & 1.26 & 0.16 \\
\hline Austria & 0.70 & 1.74 & 0.69 & 0.98 & 2.04 & 0.08 & 0.88 & 1.89 & -0.02 \\
\hline Belgium & 0.43 & 0.75 & 0.44 & 1.00 & 2.93 & 0.00 & 0.78 & 2.50 & -0.29 \\
\hline Canada & 0.82 & 1.31 & 0.69 & 0.94 & 1.55 & 0.47 & 0.81 & 1.52 & 0.39 \\
\hline Denmark & 0.77 & 1.75 & 0.78 & 0.98 & 3.83 & 0.21 & 0.94 & 3.73 & 0.20 \\
\hline Finland & 0.89 & 3.18 & 0.85 & 0.96 & 2.81 & 0.37 & 0.92 & 2.77 & 0.34 \\
\hline France & 0.90 & 2.70 & 0.86 & 0.97 & 3.45 & 0.50 & 0.93 & 3.45 & 0.49 \\
\hline Germany & 0.59 & 0.99 & 0.48 & 1.00 & 2.20 & 0.15 & 0.95 & 2.20 & 0.11 \\
\hline Iceland & 0.80 & 2.40 & 0.85 & 0.90 & 2.45 & 0.28 & 0.71 & 2.32 & 0.25 \\
\hline Italy & 0.51 & 0.90 & 0.10 & 0.98 & 1.69 & 0.48 & 0.68 & 1.42 & 0.34 \\
\hline Japan & 0.61 & 0.85 & 0.49 & 0.93 & 0.99 & 0.24 & 0.75 & 0.89 & 0.01 \\
\hline The Netherlands & 0.83 & 2.05 & 0.76 & 0.85 & 2.07 & 0.74 & 0.85 & 2.07 & 0.74 \\
\hline Norway & 0.79 & 2.05 & 0.72 & 0.96 & 2.69 & 0.31 & 0.84 & 2.48 & 0.26 \\
\hline Sweden & 0.85 & 2.64 & 0.84 & 0.98 & 2.98 & 0.13 & 0.95 & 2.96 & 0.12 \\
\hline United Kingdom & 0.86 & 1.58 & 0.68 & 1.00 & 3.96 & 0.46 & 0.91 & 3.76 & 0.45 \\
\hline United States & 0.83 & 1.45 & 0.67 & 0.96 & 1.68 & 0.48 & 0.76 & 1.47 & 0.41 \\
\hline Mean & 0.74 & 1.70 & 0.65 & 0.94 & 2.39 & 0.34 & 0.82 & 2.29 & 0.25 \\
\hline
\end{tabular}

Note: The moments of the current account and changes in consumption predicted by the SI model (the left panel), the hybrid SI model (the middle panel) and the actual moments (the right panel). The SI model in the left panel is based on $\tilde{\omega}$ that minimizes the objective function $Q(\theta)$ under a restriction $\lambda=0$. The objective function $Q(\theta)$ is defined in the main text. The hybrid SI model is based on unrestricted estimates $\hat{\omega}$ and $\hat{\lambda}$. The right panel reproduces the right panel of Table 3 to facilitate comparisons with the models. See the footnote of Table 3 for the other detail. 
Table 5: Estimates of $\omega$ and $\lambda$ and $Q(\theta)$ in the SI models

\begin{tabular}{|c|c|c|c|c|c|c|}
\hline & \multicolumn{2}{|c|}{ SI model } & \multicolumn{3}{|c|}{ Hybrid SI model } & \multirow{2}{*}{$\begin{array}{c}H_{0}: \lambda=0 \\
Q(\tilde{\theta})-Q(\hat{\theta})\end{array}$} \\
\hline & $\tilde{\omega}$ & $Q(\tilde{\theta})$ & $\hat{\omega}$ & $\hat{\lambda}$ & $Q(\hat{\theta})$ & \\
\hline Australia & 0.49 & 9.95 & 0.49 & 0.00 & 9.95 & 0.00 \\
\hline Austria & 0.67 & 16.93 & 0.96 & 0.75 & 0.85 & $16.08^{* *}$ \\
\hline Belgium & 0.43 & 43.43 & 0.98 & 1.00 & 8.14 & $35.29^{* *}$ \\
\hline Canada & 0.67 & 3.74 & 0.87 & 0.55 & 1.49 & 2.25 \\
\hline Denmark & 0.76 & 20.63 & 0.95 & 0.41 & 0.12 & $20.51^{* *}$ \\
\hline Finland & 0.83 & 5.27 & 0.92 & 0.52 & 0.14 & $5.13^{*}$ \\
\hline France & 0.84 & 9.04 & 0.93 & 0.34 & 0.14 & $8.90^{* *}$ \\
\hline Germany & 0.47 & 17.64 & 0.98 & 0.99 & 0.30 & $17.35^{* *}$ \\
\hline Iceland & 0.83 & 13.78 & 0.91 & 0.32 & 1.53 & $12.26^{* *}$ \\
\hline Italy & 0.09 & 5.35 & 0.94 & 0.77 & 4.57 & 0.78 \\
\hline Japan & 0.48 & 10.72 & 0.89 & 0.78 & 3.61 & $7.11^{* *}$ \\
\hline Netherlands & 0.74 & 0.04 & 0.76 & 0.08 & 0.00 & 0.03 \\
\hline Norway & 0.71 & 10.29 & 0.93 & 0.60 & 1.36 & $8.93^{* *}$ \\
\hline Sweden & 0.82 & 25.43 & 0.96 & 0.63 & 0.08 & $25.35^{* *}$ \\
\hline United Kingdom & 0.67 & 6.20 & 0.97 & 0.81 & 0.66 & $5.54^{*}$ \\
\hline United States & 0.65 & 4.18 & 0.89 & 0.67 & 2.61 & 1.57 \\
\hline Mean & 0.63 & 12.66 & 0.89 & 0.58 & 2.22 & 10.44 \\
\hline
\end{tabular}

Note: Estimates of the degree of information rigidity and the degree of imperfect capital mobility in the SI models. The left panel (SI model) presents $\tilde{\omega}$ under a restriction $\lambda=0$ and the value of the objective function $Q(\tilde{\theta})$ under the same restriction. The middle panel (Hybrid SI model) shows unrestricted estimates $\hat{\omega}$ and $\hat{\lambda}$ and $Q(\hat{\theta})$, where $\hat{\theta}=(\hat{\omega}, \hat{\lambda})^{\prime}$. The right panel reports the test statistic for the null hypothesis of $\lambda=0$. The asterisks $*$ and ${ }^{* *}$ indicate that the null hypothesis is rejected at the five percent and the one percent significance level, respectively. 